\title{
Cyberbullying through the lens of social in uence: Predicting cyberbullying perpetration from perceived peer-norm, cyberspace regulations and ingroup processes
}

\author{
Valentina Piccoli ${ }^{\mathrm{a}}$, Andrea Carnaghi ${ }^{\mathrm{a}}$, Michele Grassi ${ }^{\mathrm{a}}$, Marta Stragà ${ }^{\mathrm{a}}$, Mauro Bianchi ${ }^{\mathrm{b}}$ \\ ${ }^{a}$ Department of Life Sciences, University of Trieste, Italy \\ ${ }^{\mathrm{b}}$ HEI-lab, Lusófona University, ISCTE-Lisbon University Institute, Italy
}

\section{A R T I C L E I N F O}

\section{Keywords:}

Cyberbullying

Social in uence

Social identity

Peer-norm

Identi cation

Prototypicality

\begin{abstract}
A B S T R A C T
In the present research we analyzed the social in uence mechanisms that back the relation between peer group norms regarding cyberbullying behaviors and individual cyberbullying perpetration. In a sample of adolescents $(\mathrm{N}=3511$, age: $M=16.27, S D=1.58$ ), we showed that the relation between perceived peer-norm and cyberbullying perpetration was moderated by two distinct social in uence mechanisms. Speci cally, when individuals' lack of knowledge regarding appropriate behaviors in cyberspace (i.e., cyberspace regulations), levels of perceived peer-norm regarding cyberbullying behaviors positively in uence the participants' engagement in cyberbullying perpetration (i.e., informational social in uence). Moreover, we showed that the higher the support of perceived peer-norm regarding cyberbullying behaviors the higher the levels of cyberbullying perpetration, especially for the higher (vs. lower) levels of identi cation with peers as the ingroup; this relation was additionally enhanced at increasing levels of adolescents' ingroup prototypicality (i.e., referential informative social in uence). The results demonstrated that the two social in uence mechanisms work independently and likely contribute to predict participants engagement in cyberbullying perpetration. Results are discussed with respect to the current literature regarding the social in uence mechanisms underlying cyberbullying. The implications of these ndings for practical interventions are explored.
\end{abstract}

\section{Introduction}

The use of electronic technologies to communicate (e.g., SMS, email, social networks, digital imaging, and online games) is widely disseminated in Western society (Li, Smith, \& Cross, 2012). Although electronic communication might improve individual interactions (Kowalski, Giumetti, Schroeder, \& Lattanner, 2014; Kowalski, Limber, \& McCord, 2019), it has also o ered individuals a virtual arena in which to engage in discriminatory behaviors in general, and cyberbullying in particular (Kowalski et al., 2014; Li et al., 2012). According to Smith et al. (2008, p. 376), cyberbullying refers to an aggressive, intentional act carried out by a group or individual, using electronic forms of contact, repeatedly and over time against a victim who cannot easily defend him- or herself . This de nition has further been elaborated on in additional theoretical and empirical works. First, although cyberbullying typically occurs via electronic forms of contact, it is not limited to cyberspace and can also involve direct forms of bullying (Beran \& Li, 2008; Langos, 2012). Second, while some authors argue that the repetition of cyberbullying acts is a constituent feature of the de nition of cyberbullying (DeSmet et al., 2014; Nocentini et al., 2010; Schultze-Krumbholz et al., 2015), other scholars claim that posting content online, for instance, might be seen per se as a form of repetition since this content can be viewed and forwarded repeatedly without the active contribution of the perpetrator (Kowalski, Limber, \& Agatston, 2008; Menesini \& Nocentini, 2009; Schultze-Krumbholz et al., 2015). Although some authors consider the repetition of cyberbullying an informative element to the perceived gravity of cyberbullying incidents, these scholars do not consider repetition a key feature in the de nition of cyberbullying (DeSmet et al., 2014; Kiriakidis \& Kavoura, 2010; Tokunaga, 2010). Third, the relationship between the cyberbullying perpetrator and victim is characterized by a power imbalance that sees, at least in certain cases, an advantage of the perpetrator over the victim. However, the power imbalance between the cyberbullying perpetrator and victim also depends on their technical abilities with information communication technologies (e.g., Brighi, Menin, Skrzvpiec, \& Guarini, 2019; Del Rey et al., 2015; Hinduja \& Patchin, 2008; Menesini \&

Corresponding author. University of Trieste, Department of Life Sciences, Psychology Unit, Via Weiss, 21 Building W, 34100, Trieste, Italy.

E-mail address: vpiccoli@units.it (V. Piccoli). 
Nocentini, 2009; Pozzoli \& Gini, 2019; Vandebosch \& Van Cleemput, 2008). Moreover, the anonymity provided by the electronic technologies can also help create a power advantage for the victims to get revenge on their perpetrators (DeHue, Bolman, \& Völlink, 2008; Li, 2007; Schenk \& Fremouw, 2012; Ybarra \& Mitchell, 2004).

Cyberbullying can take distinct forms, including harassment (i.e., sending o ensive and vulgar messages to a target), exclusion (i.e., marginalizing and/or excluding a target from a group), impersonation (i.e., stealing a target's credentials and taking over their pro les), outing and trickery (i.e., sharing a target's personal data and information without consent, see Pyżalski, 2012; Willard, 2007).

The prevalence of cyberbullying has been demonstrated in several studies and in di erent geographical areas (Görzig \& Frumkin, 2013; Lobe, Livingstone, Olafsoon, \& Vodeb, 2011). However, the prevalence of cyberbullying varies across studies depending on the cultural contexts, the characteristics of the research samples (Kowalski et al., 2019), the methodological issues, such as the de nition of phenomenon (Brighi, Menin, Skrzypiec, \& Guarini, 2019, p. 2), the recall period (e.g., lest year vs. last month; Brochado, Soares, \& Fraga, 2017, p. 527), the conservative versus liberal criterion employed to estimate the occurrence of cyberbullying (Kowalski et al., 2019), and the assessment instruments (Brochado et al., 2017).

In a recent review across 159 studies, Brochado et al. (2017) demonstrated that rates of the prevalence of cyberbullying perpetration within one year ranged from $3.0 \%$ to $39.0 \%$, and the rates of the prevalence of cyberbullying victimization ranged from $1.0 \%$ to $61.1 \%$ (see, also Arnarsson et al., 2019; Ga ney, Farrington, Espelage, \& Tto 2018; Jadambaa et al., 2019; Modecki, Minchin, Harbaugh, Guerra, \& Runions, 2014).

Moreover, the National Crime Prevention Council and Harris Interactive have reported that over $40 \%$ of American adolescents are the victims of cyberbullying (Bhat, 2008). In the European context, 18\% of Internet-using children have experienced cyberbullying and online harassment (Hasebrink, Livingstone, Haddon, \& ólafsson, 2009). The EU Kids Online study of over 25,000 young individuals (age range: 9 to 16 ) in 25 European countries showed that $19 \%$ of children reported that they have experienced cyberbullying perpetration (Lobe, Livingstone, ólafsson, \& Vodeb, 2011). In Belgium, one third of the interviewed students indicated that they have been the victims of cyberbullying, and approximately one fth of students interviewed reported that they have engaged in cyberbullying behaviors (Walrave \& Heirman, 2011). Similarly, in the Italian context, which is the setting of the current research, $22.4 \%$ of Italian adolescents declared that they have been the victim of cyberbullying at least once (Brighi, Guarini, Melotti, Galli, \& Genta, 2012; Genta, Brighi, \& Guarini, 2009; Istituto Nazionale di Statistica, 2014).

Given the pervasiveness of cyberbullying, several studies have attempted to better understand the psychological correlates of cyberbullying perpetration and the role of contextual variables in promoting/ inhibiting cyberbullying perpetration (Calvete, Orue, Estévez, Villardón, \& Padilla, 2010; Fanti, Demetriou, \& Hawa, 2012; Ubertini, 2011; Williams \& Guerra, 2007). Among the contextual variables, social in uence processes in general, and peer group in uence in particular have been found to play a pivotal role in promoting cyberbullying behaviors (Du y \& Nesdale, 2009; 2010; Festl, Scharkow, \& Quandt, 2013; Hinduja \& Patchin, 2013; Pabian \& Vandebosch, 2014; Sasson \& Mesch, 2014; 2017). Social in uence occurs when individuals shape their behaviors, beliefs, and attitudes by complying with group expectations (Deutsch \& Gerard, 1955). Research addressing the relationship between social in uence and cyberbullying behaviors has shown that adolescents who expect the peer group to condone, rather than condemn cyberbullying (i.e., peer group norm), also display high levels of intention to engage in cyberbullying behaviors (Heirman \& Walrave, 2012; Hinduja \& Patchin, 2013). Similarly, the stronger the perceived support by the peer group to engage in cyberbullying, the higher the frequency of being involved in cyberbullying acts as perpetrators (Pabian \& Vandebosch, 2014). Together these ndings suggested that the peer group norm concerning cyberbullying behaviors shapes the proclivity of adolescents to engage in acts of cyberbullying (Hinduja \& Patchin, 2013; Sasson \& Mesch, 2017).

Despite these ndings testifying to the role of peer group norms in determining cyberbullying perpetration, the aforementioned studies failed to highlight the psychological processes that may account for the relation between peer group norms and cyberbullying. The current research intends to 11 this gap by addressing the speci c social and cognitive underpinnings of the relation between cyberbullying peer group norms and adolescents tendency to engage in cyberbullying behaviors.

\subsection{Mechanisms of social in uence}

Accumulated evidence in social psychology has demonstrated that at least two mechanisms could account for the impact of group norms on one's own behavior, namely the informational and referential informative social in uence (Abrams \& Hogg, 1990; Deutsch \& Gerard, 1955).

To navigate the social environment, individuals may experience subjective uncertainty concerning the correctness of their attitudinal and behavioral position, especially when they come across situations that involve a di erent degree of ambiguity. In such situations, individuals likely engage in social comparisons with others to verify the correctness of their attitudes (Cialdini, 1993; Festinger, Schacter, \& Back, 1950). This process of social comparison is backed by the individuals' motivation to gain accurate beliefs about social reality. In such a case, individuals may take on the group norm as a way to gain an appropriate appraisal of a given attitudinal object. This process is referred to as informational social in uence. The informational social in uence is driven by individuals' beliefs in the validity of the views of others, and by a subjective and genuine reason to agree with others' attitudinal positions (Abrams \& Hogg, 1990). In sum, informational social in uence claims that individuals adopt others' beliefs and behaviors because they consider others attitudes, beliefs and behaviors as a valid interpretation of reality. The reason to agree with the source of in uence is especially enhanced when the individual target of in uence lacks personal knowledge regarding a given attitudinal object (Allen, 1965; French \& Raven, 1959).

Another psychological process that may account for the social inuence of group norms on individuals' behaviors is the referential informative social in uence (Abrams \& Hogg, 1990; Hogg, Abrams, Otten, \& Hinkle, 2004), which stems from the Self-Categorization Theory (i.e., SCT, Turner, 1985; 1991). SCT suggests that individuals constantly categorize themselves and derive self-representation from the representation of the category in which the self is included, namely the ingroup. By categorizing the self into an ingroup, the representation of the self shifts from an individual-based identity (i.e., the individual as a unique person in comparison to other individuals) to a group-based identity, also referred to as social identity (i.e., the part of the individual's self-concept that derives from membership in a signi cant social group). The referential informative social in uence considers the social in uence process as an intra-group outcome. Speci cally, the referential informative social in uence claims that social identity allows one to discover the ingroup norms through observation, interaction with other ingroup members, and assignment of the ingroup norms to the self. In so doing, group members adopt the ingroup norms as valid standards to shape one's own attitudes, beliefs, and behaviors. Moreover, adopting the ingroup norms allows members to be truly recognized as members of that group by external observers (Carnaghi \& Yzerbyt, 2006; 2007).

The referential informative social in uence is moderated by two psychological factors, namely ingroup prototypicality and ingroup identi cation. Despite ingroup prototypicality and ingroup identi cation representing two di erent constructs of social identity (Kashima, 
Kashima, \& Hardie, 2000), they jointly contribute to align group members' behaviors with ingroup norms (Goode, Balzarini, \& Smith, 2014; Jetten \& Spears, 2003; Jetten, Spears, \& Manstead, 1997). First, the ingroup prototypicality of a given member refers to the position that an individual holds within the ingroup, thus re ecting the extent to which the member is a central or peripheral member (Jetten et al., 1997; Turner, Hogg, Oakes, Reicher, \& Wetherell, 1987; Turner, 1991). Central members, more so than peripheral members are motivated to comply with and thus support the ingroup norms by behaving accordingly (Hogg, 2007; Jetten et al., 1997). In a relevant study, Du y and Nesdale (2010; see also Du y \& Nesdale, 2009) experimentally manipulated the adolescent ingroup norms (aggression vs. helping behaviors), adolescents' ingroup prototypicality (central vs. peripheral) and assessed participants aggressive intention. Results showed that compared to peripheral participants, central participants reported more aggressive intention only when the ingroup norms promoted aggression. Together these ndings indicated that central members are motivated to maintain the ingroup norms and are more likely to engage in ingroup normative behaviors compared to peripheral members.

Second, ingroup identi cation is de ned as the importance of the ingroup to de ne one's self-representation, the sense of connectedness one feels towards other members, and the a ective reactions triggered by belonging to this ingroup (Jetten et al., 1997; Turner, 1991; Turner et al., 1987). Empirical evidence has shown that increased levels of ingroup identi cation are associated with stronger ingroup normative behaviors. For instance, Terry and Hogg (1996) showed that participants' behavioral intentions are more aligned with the perceived ingroup norms (i.e., frequency of physical exercise per week), when participants display high, compared to low levels of ingroup identi cation (for similar results, see also Schmitt \& Branscombe, 2001).

The current research recasts the analysis of cyberbullying within the frame of social in uence theory, thus broadening the understanding of the manner in which peer group norms contribute to the emergence and enactment of cyberbullying behaviors. Speci cally, and in line with the two di erent social in uence mechanisms discussed above, we rst analyzed cyberbullying perpetration as a potential product of the informational social in uence as well as of the referential informative social in uence mechanism. Based on these analyses, we derived speci c hypotheses concerning the manner in which peer norms concerning cyberbullying are associated with personal engagement in cyberbullying acts.

\subsection{Social processes in the context of cyberbullying}

The signi cance of the group norm in regards to the perpetration of cyberbullying can be derived by two distinct models of social in uence. First, and in line with the informational social in uence mechanism, it might be plausible that when adolescents lack knowledge about appropriate behavior in cyberspace, such as the laws ruling the use of cyberspace, they might experience a certain degree of uncertainty in regard to acceptable behaviors in such a virtual environment. In this situation, adolescents could rely on the group peer norms about cyberbullying acts and behave accordingly. If this is the case, it could be possible that the stronger the support of the group peer norms to cyberbullying behaviors, the higher the engagement in cyberbullying perpetration, accompanied by decreased levels of knowledge about laws ruling the use of cyberspace. Second, and consistent with the referential informative social in uence mechanism, it might be plausible that the stronger the support of the group peer norms to cyberbullying behaviors, the stronger the participants' engagement in cyberbullying perpetration, and this association could be moderated by participants' level of ingroup identi cation and ingroup prototypicality. Speci cally, higher levels of ingroup identi cation could strengthen the association between cyberbullying group norms and participants engagement in cyberbullying perpetration, and this association would be enhanced at increasing levels of ingroup prototypicality.
Moreover, cyberbullying is a multidimensional social process which theoretically and empirically comprises both cyber-perpetration and cyber-victimization (Baldry, Farrington, \& Sorrentino, 2015; Del Rey et al., 2015; Festl, Vogelgesang, Scharkow, \& Quandt, 2017; Kowalski et al., 2014; Rice et al., 2015; Schultze-Krumbholz et al., 2015; Smith et al., 2008; Ybarra \& Mitchell, 2004). Indeed, individuals who are the perpetrator can also be the victim of cyberbullying, and vice versa (Espelage \& Swearer, 2003; Gradinger, Strohmeier, \& Spiel, 2009; Kowalski et al., 2014; Li, 2007; Smith et al., 2008; Walrave \& Heirman, 2011; Yang \& Salmivalli, 2013; Ybarra \& Mitchell, 2004).

The analysis of the bystander perspective is of particular importance with respect to the emergence of the peer norms, and contributes to gaining a broader understanding of the social in uence processes within the group of peers. Indeed, the cyberbullying does not occur in isolation but may, at least in certain cases, extend outside the perpetrator and victim setting and may include the bystander. Individual members typically discover and then endorse group norms by comparing their attitudinal positions and behaviors with peers' attitudes and behaviors (Abrams \& Hogg, 1990; Hogg et al., 2004; Pozzoli \& Gini, 2010). Hence, witnessing cyberbullying behaviors, as in the case of the bystander, may contribute to the discovery and then the endorsement of the peer group norm concerning cyberbullying. Also, and by behaving according to the group norm (e.g., do not intervene and allow cyberbullying aggression to continue), the bystander plays a signi cant role in maintaining and reinforcing bullying behaviors in general (Craig, Pepler, \& Atlas, 2000; DeSmet et al., 2014; Oh \& Hazler, 2009; O'Connell, Pepler, \& Craig, 1999; Salmivalli, 1999) and cyberbullying in particular (Bastiaensens et al., 2016).

\subsection{The present study}

In the current study, given the dynamic and social nature of cyberbullying, we assessed the cyberbullying perpetration, cyber-victim perspective, and the cyber-bystander perspective. Moreover, and, given the focus of the current research on the e ect of group norms on group members' behavior, participants' perception of the extent to which ingroup friends accepted and promote cyberbullying behaviors was assessed (i.e., peer norm). Previous research measuring the ingroup norm typically presented participants with a list of behaviors relevant to the research aim, and asked participants about the extent to which these behaviors were approved of by the ingroup (Baker \& White, 2010; Hamilton \& White, 2008; Louis, Taylor, \& Douglas, 2005; White, Hogg, \& Terry, 2002; White, Smith, Terry, Greenslade, \& McKimmie, 2009). It is worth noting that this measure allows researchers to adjust the type of ingroup according to the referent group under investigation, that being friends, for example (Baker \& White, 2010; Hamilton \& White, 2008; Sasson \& Mesch, 2014; 2017) parents (Liu, Fang, Deng, \& Zhang, 2012; Malcolm et al., 2013). Also, the selected behaviors entered in the perceived peer-norm measure were the same as those used to assess participants' personal engagement in those behaviors (i.e., cyberbullying perpetration). This procedure is required when intending to assess the relation between ingroup norm and personal behaviors (Terry \& Hogg, 1996). Di erent studies have adopted this procedure concerning the assessment of the ingroup norm related to speci $\mathrm{c}$ behaviors and participants engagement in these behaviors (Baker \& White, 2010; Hamilton \& White, 2008; White et al., 2009), thus attesting to the robustness of this assessment procedure.

Moreover, and in line with our claim that adolescents may rely on peer norms concerning cyberbullying behaviors, especially when they lack knowledge about appropriate behavior in a virtual environment in general, and about the laws ruling the use of cyberspace in particular (i.e., informational social in uence), in the current study we assessed participants' knowledge regarding the laws ruling the use of cyberspace (i.e., cyberspace regulations). In particular, participants were presented with behaviors which take place in cyberspace and they were asked to indicate whether, in their view, each of the behaviors was legal or 
illegal according to Italian law. Hence, we ad hoc created the cyberbullying regulations measure. Taking into account that, at least from a socio-cognitive perspective, social knowledge is typically structured upon content and evaluative components (Dovidio, Evans, \& Tyler, 1986; Fiske, 1982), we assessed participants knowledge to correctly detect illegal cyberbullying behaviors (i.e., content-based component) and the anticipated seriousness of the outcome related to engaging in such behaviors (evaluative components).

In line with the informational social in uence mechanism (Abrams \& Hogg, 1990) we hypothesized a signi cant perceived peer-norm by cyber-space regulations interaction in predicting cyberbullying perpetration (i.e., the outcome variable). Speci cally, we hypothesized that the higher the level of perceived peer-norm, the higher the level of cyber-bullying perpetration at decreasing levels of cyberspace regulations (Hypothesis 1).

Moreover, we assert that, and in line with the referential informative social in uence mechanism, two important indicators of social identity may moderate the relationship between peer norm and cyber bullying behaviors, namely ingroup prototypicality and ingroup identi cation. These variables are of particular importance since the referential informative social in uence suggests that the compliance with the peer norm is a product of intra-group dynamics, whereby ingroup members endorse the peer norm to the extent to which they identify with the ingroup and occupy a central role within the ingroup. Hence, the assessment of ingroup prototypicality and ingroup identi cation appears to be necessary in order to analyze the validity of the referential informative social in uence mechanism in accounting for cyberbullying perpetration. Speci cally, individuals' self-perception of their representative position within the peer group was measured to assess participants ingroupperceived level of prototypicality (i.e., ingroup prototypicality). In social psychology, the ingroup-perceived level of prototypicality was assessed by a single item developed by Jetten et al. (1997) and subsequently used in various social psychology studies (see also Easterbrook \& Vignoles, 2013; Méndez, Gómez, \& Tropp, 2007). The psychometric validation of this single item measure of prototypicality has been supported by various studies (Easterbrook \& Vignoles, 2013; Jetten et al., 2007; Méndez et al., 2007; Obst, White, Mayor, \& Baker, 2011). Indeed, previous studies that relied on the single item measure showed that ingroup-perceived level of prototypicality was positively associated with the relevant dimension of the social identity (e.g., cognitive centrality, Obst, White, Mavor, \& Baker, 2011).

Moreover, two indicators of ingroup identi cation were also employed in the current study. Speci cally, we assessed two relevant dimensions of ingroup identi cation, namely cognitive identi cation (i.e., the overlapping of the self with the peer group) and a ective identi cation (i.e., the feelings of belongingness to the peer group). In particular, the Inclusion of the Other in the Self scale (i.e., IOS; Aron, Aron, \& Smollan, 1992) was used in the current research as a cognitivebased identi cation measure. The rationale that backs this measure is that the cognitive representation of the self can be socially expanded to other individuals (Aron, Aron, Tudor, \& Nelson, 1991). This assumption has been further elaborated by social psychologists working in the SIT (Tajfel \& Turner, 1979) and SCT (Turner et al., 1987). Indeed, and according to these theories, the self can be expanded at various levels of inclusion, spanning from the individual to the group level. As far as the group level is concerned, the self is de ned as similar and equivalent to a given group (i.e., ingroup) in contrast to an alternative group (i.e., outgroup; Turner et al., 1987). In agreement with, Tropp and Wright (2001) suggested the Inclusion of the Ingroup in the Self (i.e., IIS; Tropp \& Wright, 2001) as an adapted version of the IOS. The psychometric validation of this single item measure of ingroup identi cation has been supported by other studies (Schubert \& Otten, 2002; Tropp \& Wright, 2001). Speci cally, IIS was found to be signi cantly correlated with the similarity of descriptive characteristics attributed to the self and to the ingroup (Tropp \& Wright, 2001). In a discriminant analyses, Schubert and Otten (2002) showed that the IIS was a valid tool to assess the cognitive, but not the evaluative, component of the general construct of ingroup identi cation, which, in the quoted research, was assessed with a traditional self-reported measure of ingroup identi cation (Klink, Mummendey, Mielke, \& Blanz, 1998).

As previously mentioned, the general construct of ingroup identication is multidimensional, as it includes both the cognitive and affective components. Hence, we decided to rely also on an a ectivebased identi cation measure, given that the IIS scale was speci cally tied to assess the cognitive component of ingroup identi cation. In this respect, the ingroup identi cation scale developed by Kiesner, Cadinu, Poulin, and Bucci (2002) meets our requirement to adopt an assessment tool of the a ective-based ingroup identi cation.

Grounded in the referential informative social in uence mechanism (Abrams \& Hogg, 1990; Hogg et al., 2004), which stems from Self Categorization Theory (Turner, 1985; 1991) we hypothesized a signi cant interaction between perceived peer-norm, ingroup identi cation and ingroup prototypicality in predicting cyberbullying perpetration. Speci cally, we hypothesized that the higher the level of perceived cyber friend norm, the higher the level of cyberbullying perpetration at increasing levels of ingroup identi cation and ingroup prototypicality (Hypothesis 2).

Finally, habits regarding Smartphone/Internet use and demographic measures (i.e., gender, age, and parents level of education) were assessed in the current study and then employed as control variables in the statistical analyses, since previous theoretical and empirical e orts have suggested that these variables are relevant when analyzing the predictors of cyberbullying.

As for habits regarding Smartphone/Internet use, previous studies showed that the higher the frequency of Smartphone/Internet use, the higher the probability of engaging in cyberbullying behaviors (Mishna, Khoury-Kassabri, Gadalla, \& Daciuk, 2012; Rice et al., 2015; Ybarra \& Mitchell, 2004).

As for the association between participants gender and cyberbullying perpetration, research in the international (Aricak et al., 2008; Smith, 2012; Walrave \& Heirman, 2011; Wang, Iannotti, \& Nansel, 2009) as well as in the Italian context (Baroncelli \& Ciucci, 2014; Guarini, Passini, Melotti, \& Brighi, 2012; Palermiti, Servidio, Bartolo, \& Costabile, 2017) has found that boys engage in cyberbullying behaviors as perpetrators more than girls. However, other results did not show any signi cant association between participant gender and cyberbullying perpetration (DeHue et al., 2008; Griezel, Finger, BodkinAndrews, Craven, \& Yeung, 2012; Hinduja \& Patchin, 2008; Menesini, Nocentini, \& Camodeca, 2013; Smith et al., 2008; Williams \& Guerra, 2007; Ybarra \& Mitchell, 2004). Taking into consideration that research ndings on this issue were not entirely coherent (Baroncelli \& Ciucci, 2014; DeHue et al., 2008; Griezel et al., 2012; Guarini et al., 2012; Hinduja \& Patchin, 2008; Menesini et al., 2013; Palermiti et al., 2017; Smith, 2012; Smith et al., 2008; Walrave \& Heirman, 2011; Wang et al., 2009; Williams \& Guerra, 2007; Ybarra \& Mitchell, 2004), we explored the association between gender and cyberbullying perpetration.

As far as the relation between participants' age and participants' engagement in cyberbullying perpetration was concerned, empirical evidence has shown that the older the participants, the higher the probability of engaging in cyberbullying behaviors (Hinduja \& Patchin, 2008; Kowalski \& Limber, 2007; Ybarra, Mitchell, Finkelhor, \& Wolak, 2007; Ybarra, Mitchell, Wolak, \& Finkelhor, 2006). However, additional research has shown that younger adolescents were more frequently inclined to engage in cyberbullying behaviors than older adolescents (DeHue et al., 2008; Ševčíková \& Šmahel, 2009). Given the alternative patterns of the association between participants' age and participants' engaging in cyberbullying perpetration, the current research explored whether the two variables were or were not signi cantly associated (Patchin \& Hinduja, 2008; Smith et al., 2008), and if a signi cant association occurred, whether an increased level of participants age corresponded to either increased (Hinduja \& Patchin, 2008; Kowalski \& Limber, 2007; Walrave \& Heirman, 2011; Ybarra et al., 2006, 2007; Ybarra \& Mitchell, 2004) or decreased (DeHue et al., 2008; Ševčíková \& Šmahel, 2009) levels of cyberbullying perpetration. 
Finally, participants were asked to report their parents' level of education. In a few studies, this variable was assessed to describe the sample but was not used as a predictor of cyberbullying perpetration, namely the outcome variable (Brighi et al., 2012). Additional studies showed that parental level of education did not a ect cyberbullying behaviors (Makri-Botsari \& Karagianni, 2014), while other ndings showed that participants with at least one parent with a higher level of education, were less often perpetrators than students whose parents do not have a high degree of education (Låftman, Modin, \& Östberg, 2013). Given the limited evidence on the relation between parents' level of education and cyberbullying perpetration, we made an exploratory test of the association between these two variables, knowing that previous research suggested that either no association occurred between parents' level of education and cyberbullying perpetration or if enhanced levels of parent's education corresponded lower levels of engagement in cyberbullying perpetration.

\section{Method}

\subsection{Participants}

We recruited $N=3511$ students ( $n=1916$ female students, $n=1489$ male students, $n=106$ did not report their gender) from nineteen high schools in north Italy that voluntarily took part in the research. Participants age ranged from 13 to $22(M=16.27$, $S D=1.58 ; n=150 \mathrm{did}$ not report their age). Moreover, $28,3 \%$ of participants were rst-year students (year 10 in the English Education System), $16,7 \%$ of respondents were second-year students, $35.2 \%$ of participants were third-year students, and $16.5 \%$ of respondents were fourth-year students. Finally, 3.4\% of respondents did not report their year.

\subsection{Procedure}

This study received ethical approval from the University Ethics Committee. Secondary schools were contacted and consent was obtained from the school board. The study was presented as a research on the use of new media and social behaviors'. Parental consent was given before students participation in the study. The study was organized in a computer classroom within the school. Data were collected through anonymous self-report questionnaire during school hours via a Web survey (i.e., SurveyMonkey). Participants were asked to $\mathrm{ll}$ in the questionnaire individually after providing their informed written consent. The questionnaire took approximately $30 \mathrm{~min}$ to administer.

\subsection{Measures}

Cyberbullying perpetration. The cyberbullying perpetration measure comprised ve statements that described ve distinct forms of cyberbullying behaviors (all items are given in the Appendix). For instance, participants were asked how often in the last year, via Smartphone (e.g., SMS, WhatsApp), email (e.g., mailing list) and social networks (e.g., Facebook, Instagram, Snapchat), they: a) sent o ensive and/or vulgar messages to somebody, b) published someone's personal details without consent. Participants rated their answers on a 5-point scale, ranging from 1 ( = never) to 5 (= always). Higher scores on this measure were related to a higher frequency of cyberbullying perpetration. Participants' ratings on cyberbullying perpetration measure reached a good level of reliability: $\alpha=0.69$.

Cyber-victim perspective. The same ve items of cyberbullying perpetration were adapted to assess the frequency of being cyberbullied via instant messaging, email and social networks (e.g., I have received offensive and/or vulgar messages from someone; Someone published my personal details without my consent; all items are presented in the Appendix). Participants rated their answers on a 5-point scale, ranging from $1(=$ never $)$ to 5 (= always). Participants ratings on the cyber- victim perspective reached a good level of reliability: $\alpha=0.70$.

Cyber-bystander perspective. As for cyber-bystander perspective, the ve items of cyberbullying perpetration were adapted to assess the frequency of witnessing cyberbullying behaviors via instant messaging, email and social networks. (e.g., I have read o ensive and/or vulgar messages addressed to someone who was not me; I have read details on the private life of someone who was not me; all items are reported in the Appendix). Participants rated their answers on a 5-point scale, ranging from 1 (= never) to 5 (= always). Participants ratings on cyberbystander perspective reached a good level of reliability: $\alpha=0.77$.

Perceived peer-norm. We measured the perceived peer-norm by using a scale that comprised ve items (for a similar measure, see Sasson \& Mesch, 2017; all items are reported in the Appendix). Speci cally, we presented participants with exactly the same behaviors as those employed in cyberbullying perpetration, the cyber-victim perspective and cyber-bystander perspective, and asked them to indicate the extent to which these behaviors were approved of by their friends, with whom participants were in contact via instant messages, email and social network (e.g., How many of your friends approve of/tolerate someone who posts personal details online of someone else using a Smartphone (e.g., SMS, WhatsApp), email (e.g., mailing list) and social network (e.g., Facebook, Instagram, Snapchat)? ; How many of your friends approve of/tolerate someone who send an o ensive and vulgar message to somebody using a Smartphone (e.g., SMS, WhatsApp), email (e.g., mailing list) and social network (e.g., Facebook, Instagram, Snapchat)? Participants reported their answers on a 5-point scale, ranging from 1 (= none of my friends) to 5 (= all of my friends). Higher values indicated higher perceived acceptance of cyberbullying behaviors by the peer group. Participants' ratings on perceived peer-norm reached a good level of reliability: $\alpha=0.78$.

Cyberspace regulations. Participants were presented with nine behaviors which take place in cyberspace and they were asked to indicate whether, as far as they knew, each behavior was legal or illegal according to Italian law. For each behavior, participants were asked to provide their answers by means of a binary-choice format: no, it is not legal vs. yes, it is legal. Among these behaviors, six were illegal in the Italian contexts. Importantly, among these six behaviors, three concerned cyberbullying behaviors (e.g., Gaining access to the credentials of someone without permission and acquiring their pro les; i.e., legal knowledge of cyberbullying behaviors). The other three behaviors employed as control variables, were also illegal but not related to cyberbullying and instead associated with other domains of the Web (e.g., Downloading books from the Internet without paying royalties; i.e., legal knowledge of Internet behaviors). Finally, three behaviors which were not illegal (e.g., Writing a slur word on social networks). All items are presented in the Appendix. Importantly, these three items were entered as ller items and were not further considered in the analyses. For both scale measuring participants' legal knowledge of cyberbullying behaviors and legal knowledge of Internet behaviors, we assigned the value 1 to participants' correct answer and the value 0 to wrong answers. By summing participants' correct identi cation of knowledge of cyberbullying behaviors as illegal, scores can range from zero to three (i.e., higher scores indicated higher levels of legal knowledge of cyberbullying behaviors). Similarly, by summing participants correct identi cation of knowledge regarding Internet behaviors as illegal, scores ranged from zero to three (i.e., higher scores pointed to higher levels of legal knowledge regarding Internet behaviors).

Finally, participants were asked to indicate the level of anticipated seriousness regarding engaging in the above-mentioned nine behaviors (all items are presented in the Appendix). Participants rated their answers on a 4-point scale, ranging from 1 ( = not at all serious) to 4 (= very serious). Participants ratings of the level of anticipated seriousness of the outcome related to engaging in cyberbullying behaviors ( $\alpha=0.71$ ) as well as to Internet behaviors $(\alpha=0.71$ ) reached a reasonable level of reliability.

The correlation between the legal knowledge of cyberbullying 
behaviors and the anticipated seriousness of the outcome related to engaging in cyberbullying behaviors as well as the correlation between the legal knowledge of Internet behaviors and the anticipated seriousness of the outcome related to engaging in Internet behaviors were positive and signi cant (see Table 2). We $z$-transformed the abovementioned measures. We then averaged the legal knowledge of cyberbullying behaviors and the anticipated seriousness of the outcome related to engaging in cyberbullying behaviors thus forming a unique index of cyberspace regulations. Higher values indicated higher levels of participants' knowledge of cyberspace regulations. Also, we averaged the legal knowledge of Internet behaviors and the anticipated seriousness of the outcome related to engaging in Internet behaviors thus forming a unique index of Internet regulations. Higher values indicated higher levels of participants' knowledge of Internet regulations. The Internet regulations measure was employed as a control variable.

Ingroup prototypicality. The ingroup prototypicality with respect to friends, with whom participants were in contact via instant messages, email and social networks, as the ingroup, was measured using a single item (for a similar measure, see Jetten et al., 1997): Think of your group of friends with whom you are in contact through Smartphone (e.g., SMS, WhatsApp), email (e.g., mailing list) and social networks (e.g., Facebook, Instagram, Snapchat). How much do you feel typical (i.e., characteristic) of this group of friends with whom you are in contact through Smartphone (e.g., SMS, WhatsApp), email (e.g., mailing list) and social networks (e.g., Facebook, Instagram, Snapchat)?'. Participants rated their answers by using a 4-point scale, ranging from 1 (= not at all typical) to 4 (= very much typical). Higher values on this variable indicated higher levels of ingroup prototypicality.

Ingroup identi cation. Ingroup identi cation with friends as the ingroup was assessed using two measures. To assess cognitive identi cation, we relied on the Inclusion of the Ingroup in the Self (IIS; Tropp \& Wright, 2001) single-item measure. The IIS displays seven Venn-like diagrams depicting increasing degrees of overlap between circles; one circle is labeled as representing the self, the other circle is labeled as representing the ingroup, which is the participants friends. Participants chose the picture which best described the level of closeness with friends with whom they were in contact through Smartphone and Internet. The scale was scored from 1 ( = no overlap) to 7 (= almost complete overlap).

To assess the a ective ingroup identi cation, participants were asked to respond to eight statements assessing their level of identi cation with friends with whom they are in contact through Smartphone and Internet (e.g., Is it important for you to belong to this group? , Are you happy to be described as a member of this group? ; Kiesner et al., 2002). Participants rated their answer on 7-point scales, ranging from 1 ( = no, not at all) to 7 (= yes, very much). Furthermore, participants ratings on the a ective ingroup identi cation reached a good level of reliability ( $\alpha=.88$ ). Since the two measures of identi cation were signi cantly and positively correlated (see Table 2), and following the procedures outlined by Tuscherer and Hugenberg (2014), the scores obtained by the IIS and a ective ingroup identi cation measures were $z$-transformed and then averaged together, forming a unique index of ingroup identi cation.

Habits regarding Smartphone/Internet use. Participants were asked to indicate whether or not they have a Smartphone (i.e., Yes or No), whether or not they send or receive messages using a) a Smartphone, and b) Internet (i.e., Yes or No), and whether they were part of a group via a) Smartphone, and b) Internet (i.e., Yes or No). More importantly, and in line with the procedures outlined by Camp eld (2008) participants were asked to report how often they used a) a Smartphone, and b) Internet on a weekly basis (e.g., never, rarely, 1-3 times a week, 4-6 times a week, almost every day, every day). Also, and separately for the Smartphone and Internet, participants reported the number of hours they used a) a Smartphone and b) the Internet daily (e.g., never, less than an hour a day, 2-3 h a day, 4-6h a day, more than 6h a day). First, coherently with the contents of the measures pertaining to cyberbullying perpetration, cyber-victim and cyber-bystander perspective, which assessed cyberbullying via Smartphone together with Internet, participants' usage of a Smartphone on a daily basis and participants' usage of the Internet on a daily basis were averaged to obtain an overall assessment of the usage these devices per day. In a similar vein, by averaging the participants' usage of a Smartphone on a weekly basis and participants' usage of the Internet on a weekly basis, we obtained an overall assessment of the usage of these devices per week. According to participants self-reports of Smartphone and Internet use, $96.5 \%$ of students reported owning a Smartphone, and $96.8 \%$ of the students in our sample send and receive text messages via Smartphone. Moreover, $\mathbf{8 9 . 5 \%}$ of adolescents were part of a group via Smartphone. Furthermore, $\mathbf{8 8 . 9 \%}$ of adolescents reported sending and receiving text messages via Internet and $62.2 \%$ of students were part of a group via Internet.

Demographic measures. Participants reported their gender, age, nationality, native language, the type of secondary school in which they were enrolled, the geographic location of the school (province), their class, and parents' level of education.

Except for the habits regarding Smartphone/Internet use and demographic measures that were always presented last, all the other measures were presented in a random order.

\subsection{Statistical approach}

To test the tenability of the two hypotheses we carried out a series of multiple group path analyses, within the framework of the lavaan package (Rosseel, 2012) for the R statistical program (R Core Team, 2018). ${ }^{1}$ We implemented a Full Information Maximum Likelihood estimation with robust standard errors (Huber, 1967; White, 1980), and scaled test statistics (Yuan \& Bentler, 1998). Goodness-of- $t$ indices are reported for model evaluation, and these indices were: Comparative Fit index CFI (Bentler, 1990), Root Mean Square Error of Approximation RMSEA (Schermelleh-Engel, Moosbrugger, \& Muller, 2003; Steiger \& Lind, 1980), and Standardized Root Mean Square Residual SRMR. Excellent tting models were indicated by CFI , RMSEA (90th con dence interval < 0.07), and SRMR (Hu \& Bentler, 1998; 1999). Chi-square di erence tests ( ) were used to assess statistical signi cance between nested models resulting from the restrictions on selected parameters (Satorra \& Bentler, 2001; 2010).

\section{Results}

\subsection{Descriptive results}

Means and standard deviations, numbers of items, and Cronbach'alpha for the measures employed in the current research are shown in Table 1. Intercorrelations between the variables are presented in Table 2. Table 3 showed the frequency of cyberbullying perpetration, cyber-victim perspective, and cyber-bystander perspective. In general, $34.2 \%$ of the students reported that they had bullied someone at least sometimes in the last year, $38.3 \%$ of participants responded that they were bullied at least sometimes in the last year, and $77.1 \%$ of the students reported that they had witnessed cyberbullying behaviors at least sometimes in the last year.

\subsection{Multiple group path-analyses}

In the rst multiple groups model, based on three groups of cyberspace regulations, we regressed cyberbullying perpetration (i.e., the

\footnotetext{
${ }^{1}$ The authors preliminarily approached statistical analyses with hierarchical regression models and PROCESS (Hayes, 2013) available as supplementary material, replicating the results hereby presented.
} 
Table 1

Number of items, means, standard deviations, and alpha of the measures used in the study.

\begin{tabular}{|c|c|c|c|c|}
\hline & N Items & $\alpha$ & M & SD \\
\hline Cyberbullying perpetration & 5 & .69 & 1.46 & 0.52 \\
\hline CYB_P1 & & & 1.82 & 0.97 \\
\hline CYB_P2 & & & 1.40 & 0.76 \\
\hline CYB_P3 & & & 1.49 & 0.75 \\
\hline CYB_P4 & & & 1.37 & 0.76 \\
\hline CYB_P5 & & & 1.23 & 0.60 \\
\hline Cyber-victim perspective & 5 & .70 & 1.52 & 0.56 \\
\hline CYB_V1 & & & 1.82 & 0.97 \\
\hline CYB_V2 & & & 1.44 & 0.78 \\
\hline CYB_V3 & & & 1.53 & 0.85 \\
\hline CYB_V4 & & & 1.56 & 0.87 \\
\hline CYB_V5 & & & 1.23 & 0.61 \\
\hline Cyber-bystander perspective & 5 & .77 & 2.24 & 0.76 \\
\hline CYB_B1 & & & 2.81 & 1.11 \\
\hline CYB_B2 & & & 2.14 & 1.09 \\
\hline CYB_B3 & & & 2.36 & 1.06 \\
\hline CYB_B4 & & & 2.17 & 1.09 \\
\hline CYB_B5 & & & 1.74 & 0.94 \\
\hline Perceived peer-norm & 5 & .78 & 1.84 & 0.69 \\
\hline NORM1 & & & 1.82 & 0.96 \\
\hline NORM2 & & & 1.73 & 0.92 \\
\hline NORM3 & & & 2.10 & 1.05 \\
\hline NORM4 & & & 2.02 & 0.94 \\
\hline NORM5 & & & 1.56 & 0.82 \\
\hline \multicolumn{5}{|l|}{ Cyberspace regulations } \\
\hline $\begin{array}{l}\text { legal knowledge of cyberbullying behaviors - legal/ } \\
\text { illegal }\end{array}$ & 3 & & 2.73 & 0.68 \\
\hline \multicolumn{5}{|l|}{ REGCYB_L1 } \\
\hline \multicolumn{5}{|l|}{ REGCYB_L2 } \\
\hline REGCYB_L3 & & & & \\
\hline legal knowledge of Internet behaviors - legal/illegal & 3 & & 2.38 & 0.69 \\
\hline
\end{tabular}

egal knowle dge

REGINT_L1

REGINT_L2

REGINT_L3 seriousness

REGCYB_S1

REGCYB_S2

REGCYB_S3

legal knowledge of Internet behaviors - anticipated $\quad 3 \quad \begin{array}{lllll}7 & 3 & 2.38 & 0.69\end{array}$

seriousness

REGINT_S1

REGINT_S2

REGINT_S3

Ingroup prototypicality

PROT1

Ingroup identi cation

cognitive identi cation

IDENT_IIS

a ective identi cation

IDENT_A1

IDENT_A2

IDENT_A3

IDENT_A4

IDENT_A5

IDENT_A6

IDENT_A7

IDENT_A8

Habits regarding Smartphone/Internet use

Habits of Smartphone/Internet use during the week

HAB_SW

HAB IW

Habits of Smartphone/Internet use during the day

HAB SD

HAB_ID

$\begin{array}{lll}71 & 3.62 & 0.52\end{array}$

$\begin{array}{ll}3.66 & 0.63\end{array}$

$\begin{array}{ll}3.52 & 0.68 \\ 3.67 & 0.62\end{array}$

$\begin{array}{ll}2.14 & 0.89\end{array}$

$\begin{array}{ll}2.66 & 0.83\end{array}$

$\begin{array}{ll}2.33 & 0.88\end{array}$

$\begin{array}{ll}2.66 & 0.84\end{array}$

$2.66 \quad 0.84$

$4.68 \quad 1.70$
4.68

$\begin{array}{ll}4.68 & 1.70\end{array}$

$\begin{array}{lll}88 & 4.41 & 1.33\end{array}$

$\begin{array}{ll}4.91 \quad 1.78 \\ 3.35 & 2.04\end{array}$

$3.35 \quad 2.04$

$\begin{array}{ll}5.42 & 1.61 \\ 5.03 & 1.74\end{array}$

$5.03 \quad 1.74$

$3.45 \quad 1.95$

$5.11 \quad 1.64$

$\begin{array}{ll}2.84 & 1.87\end{array}$

$5.18 \quad 1.70$

$\begin{array}{ll}5.08 & 1.15\end{array}$

$\begin{array}{ll}5.57 & 0.99\end{array}$

$4.58 \quad 1.68$

$3.23 \quad 1.05$

$\begin{array}{ll}3.43 & 1.05 \\ 3.40 & 1.07\end{array}$

$3.05 \quad 1.20$

outcome variable) on the perceived peer-norm, ingroup prototypicality, ingroup identi cation (i.e., the predictors), and on control variables (i.e., the cyber-victim and cyber-bystander perspective, habits regarding Smartphone/Internet use during the week, habits regarding Smartphone/Internet use during the day, Internet regulations, parents' level of education, participants' age and participants gender). Initially, beta coe cients were freely estimated across three groups of cyberspace regulations (i.e., cyberspace regulations groups: LOW:

HIGH: $>+1 S D ; \leq \quad \leq$ MED $\leq+1 S D$ ). Next, we constrained beta coe cients to be equal across cyberspace regulation groups separately for each predictor and control variable. Among these nested models, constraining equal e ects on cyberbullying perpetration across cyberspace regulation groups showed a signi cant worst $t$ only for perceived peer-norm, $\quad, p<.001$, whose coe cients varied substantially and signi cantly among cyberspace regulation groups. The same cross-cyberspace regulation equivalence led to a lesser change in chi-square rising for all the other predictors and control variables, and was therefore retained. The obtained nal model provided an excellent $\mathrm{t}, \quad=49.25, p=<.001 ; \mathrm{CFI}=0.976$; RMSEA $=0.035(0.024,0.047)$; SRMR $=0.013$; Table 4 shows standardized solutions. Noteworthy, the beta coe cient magnitude was greater for the perceived peer-norm and signi cantly decreased from lower levels to higher levels of cyberspace regulations. The user de ned parameter estimates feature found in the lavaan package allowed us to estimate the conditional e ect of perceived peer-norm on cyberbullying perpetration as a function of cyberspace regulations levels (1SD below the mean: $\quad, p<.001$, at the mean: $\quad, p<.001$, and 1SD above the mean: $\quad, p<.001$; see Fig. 1). In line with $H y-$ pothesis 1 , results indicated that the higher the levels of the perceived peer-norm, the higher the levels of cyberbullying perpetration at decreasing levels of cyberspace regulations. The second multiple group path-analysis considered changes in perceived peer-norm ingroup identi cation interaction e ects within three increasing levels of ingroup prototypicality (Hypothesis 2). Particularly, we reframed the previous model by considering continuous interaction terms between peer-norm and cyberspace regulations. Furthermore, we entered the interaction term between peer-norm and ingroup identi cation along with the remaining control variables. Initially, coe cients were freely estimated in the three groups of ingroup prototypicality (LOW $=$

$$
\text { MED = } 23 \text {; } \quad \text { HIGH = }
$$

). Then, we proceeded to impose equality constraints across groups of ingroup prototypicality for each of the main e ects and interaction terms of the model. In line with Hypothesis 1, peer-norm cyberspace regulations interaction term could not be excluded from the model without loss of $\mathrm{t}, \quad, p=.011$, and importantly, peer-norm cyberspace regulations interaction term can be constrained in the three groups of ingroup prototypicality, $\quad, p=.865$.

As regarding Hypothesis 2, the estimated change in the interaction term between peer-norm and ingroup identi cation as a function of ingroup prototypicality could neither be constrained,

$p=.012$, nor neutralized, $\quad, p<.001$. Restrictions applied to other remaining predictors and control variables did not signi cantly a ect the chi-square test, and these variables were retained in the nal model, which was characterized by an excellent t, $=39.14$, $p=.026 ; \quad$ CFI $=0.985 ; \quad$ RMSEA $=0.024 \quad(0.012, \quad 0.034)$; $\mathrm{SRMR}=0.013$. Table 5 shows standardized solutions. Results revealed that the interactive e ect of perceived peer-norm and ingroup identication in predicting cyberbullying perpetration was signi cant at higher and moderate levels of ingroup prototypicality. It is worth noting that increasing levels of ingroup prototypicality enhanced the size of the moderating role of ingroup identi cation on the relation between perceived peer-norm and cyberbullying perpetration.

To gain a better understanding of this interaction, we estimated the conditional e ect of the perceived peer-norm on cyberbullying perpetration as a function of ingroup identi cation (1SD below the mean, at the mean, and $1 S D$ above the mean) at di erent levels of ingroup prototypicality ( $1 S D$ below the mean and $1 S D$ above the mean, see Fig. 2) by means of user de ned estimates of the lavaan package. As far as the lower levels of ingroup prototypicality were concerned, the stronger the perceived peer-norm, the higher the frequency of cyberbullying perpetration, at higher, $\quad, p<.001$, compared to the 
Table 2

Intercorrelations of the measures used in the study.

\begin{tabular}{|c|c|c|c|c|c|c|c|c|c|c|c|c|c|}
\hline Measures & 1. & 2. & 3. & 4. & 5. & 6. & 7. & 8. & 9. & 10. & 11. & 12. & 13. 14 . \\
\hline \multicolumn{14}{|l|}{ 1. Cyberbullying perpetration } \\
\hline 2. Perceived peer-norm & .48 & & & & & & & & & & & & \\
\hline 3. Legal knowledge of cyberbullying behaviors & -.13 & -.09 & & & & & & & & & & & \\
\hline $\begin{array}{l}\text { 4. The anticipated seriousness of the outcome related to the engagement } \\
\text { in cyberbullying behaviors }\end{array}$ & -.22 & -.15 & .25 & & & & & & & & & & \\
\hline 5. IIS & .05 & -.05 & .01 & .05 & & & & & & & & & \\
\hline 6. A ective ingroup identi cation & .08 & -.07 & .01 & .07 & .35 & & & & & & & & \\
\hline 7. Ingroup prototypicality & .14 & .03 & .01 & .06 & .34 & .354 & & & & & & & \\
\hline 8. Cyber-victim perspective & .46 & .42 & -.01 & -.07 & -.01 & -.002 & .03 & & & & & & \\
\hline 9. Cyber-bystander perspective & .44 & .43 & -.07 & -.02 & .03 & .05 & .11 & .49 & & & & & \\
\hline 10. Habits of smartphone/internet use during the week & .14 & .01 & .01 & .06 & .18 & .16 & .19 & .06 & .18 & & & & \\
\hline 11. Habits of smartphone/internet use during the day & .17 & -.01 & -.08 & -.06 & .11 & .11 & .11 & .12 & .14 & .57 & & & \\
\hline 12. Legal knowledge of internet behaviors & -.14 & -.06 & .29 & .19 & -.03 & -.03 & .002 & -.07 & -.06 & -.02 & -.11 & & \\
\hline $\begin{array}{l}\text { 13. The anticipated seriousness of the outcome related to the engagement } \\
\text { in Internet behaviors }\end{array}$ & -.17 & -.11 & .09 & .30 & -.04 & -.01 & -.04 & -.03 & -.08 & -.11 & -.08 & .34 & \\
\hline 14. Parents' education & -.01 & .05 & .08 & .11 & .01 & .01 & .06 & -.006 & .05 & .06 & -.09 & .06 & .03 \\
\hline
\end{tabular}

Note: $\mathrm{p}<.05, \mathrm{p}<.01$

Table 3

Frequencies and percentages of students who were not involved or involved few times (i.e., answering never or few times ), and who were perpetrators, victims and bystanders of cyberbullying at least sometimes (i.e., answering sometimes , often or always ) for each item. Frequencies and percentage of missing values were also reported.

\begin{tabular}{lllllll} 
& \multicolumn{2}{l}{$\begin{array}{l}\text { Not involved or } \\
\text { involved few times }\end{array}$} & \multicolumn{2}{l}{$\begin{array}{l}\text { Involved at least } \\
\text { sometimes }\end{array}$} & \multicolumn{2}{l}{ Missing } \\
\cline { 2 - 7 } & $\mathrm{N}$ & $\%$ & $\mathrm{~N}$ & $\%$ & $\mathrm{~N}$ & $\%$ \\
\hline $\begin{array}{l}\text { Cyberbullying } \\
\text { perpetration }\end{array}$ & & & & & & \\
CYB_P1 & 2792 & 79.5 & 701 & 20.0 & 18 & 0.5 \\
CYB_P2 & 3174 & 90.4 & 312 & 9.0 & 25 & 0.7 \\
CYB_P3 & 3137 & 89.3 & 350 & 9.9 & 24 & 0.7 \\
CYB_P4 & 3197 & 91.1 & 294 & 8.3 & 20 & 0.6 \\
CYB_P5 & 3309 & 94.2 & 174 & 5.0 & 28 & 0.8 \\
Cyber-victim & & & & & & \\
perspective & & & & & & \\
CYB_V1 & 2723 & 77.6 & 748 & 21.3 & 40 & 1.1 \\
CYB_V2 & 3117 & 88.7 & 349 & 10.0 & 45 & 1.3 \\
CYB_V3 & 3052 & 86.9 & 423 & 12.0 & 36 & 1.0 \\
CYB_V4 & 3005 & 85.5 & 465 & 13.2 & 41 & 1.2 \\
CYB_V5 & 3309 & 94.2 & 166 & 4.8 & 36 & 1.0 \\
Cyber-bystander & & & & & & \\
$\quad$ perspective & & & & & & \\
CYB_B1 & 1368 & 39.0 & 2105 & 60.0 & 38 & 1.1 \\
CYB_B2 & 2310 & 65.8 & 1158 & 33.0 & 43 & 1.2 \\
CYB_B3 & 1989 & 56.6 & 1479 & 42.2 & 43 & 1.2 \\
CYB_B4 & 2277 & 64.9 & 1185 & 33.8 & 49 & 1.4 \\
CYB_B5 & 2811 & 80.1 & 653 & 18.7 & 47 & 1.3 \\
\hline & & & & & & \\
\hline
\end{tabular}

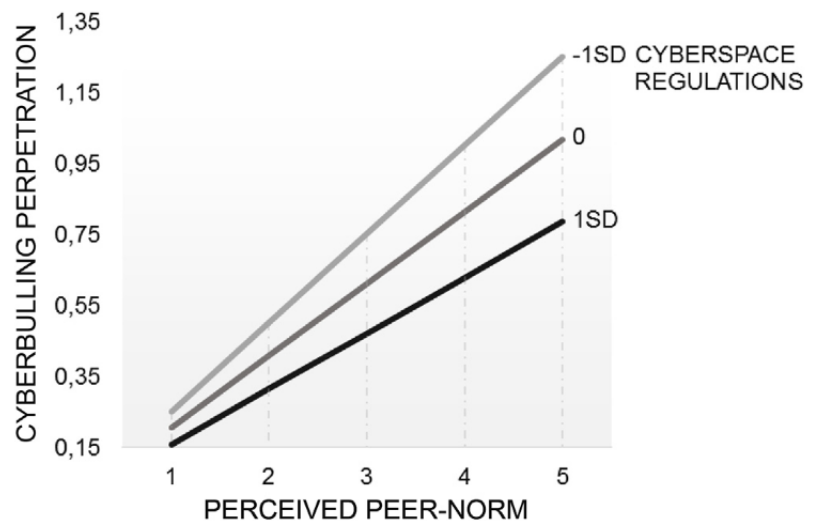

Fig. 1. Cyberbullying perpetration as a function of perceived peer-norm and cyberspace regulations.

mean, $\quad, p<.001$, and to lower levels of ingroup identi cation, ,$p<.001$. As for the higher levels of ingroup prototypicality, again, the stronger the perceived peer-norm, the higher the frequency of cyberbullying perpetration at higher, $\quad, p<.001$, compared to the mean, $\quad, p<.001$, and to lower levels of ingroup identi cation, $\quad, p<.001$.

As regarding control variables, cyber-victim perspective was a positive predictor of cyberbullying perpetration,,$p<.001$. Moreover, the participants gender signi cantly predicted

Table 4

Standardized solution for the multiple group informational social in uence model with cyberbullying perpetration as the outcome variable.

\begin{tabular}{|c|c|c|c|c|c|}
\hline Path terms & Cyberspace Regulations group & Estimate & Signi cance & CI.lower & CI.upper \\
\hline \multirow[t]{3}{*}{ Perceived peer-norm } & Low & .425 & $<.001$ & .296 & .555 \\
\hline & Med & .346 & $<.001$ & .290 & .402 \\
\hline & High & .155 & $<.001$ & .108 & .202 \\
\hline Ingroup identi cation & constrained equal & .046 & $<.001$ & .018 & .074 \\
\hline Ingroup prototypicality & constrained equal & .049 & $<.001$ & .022 & .076 \\
\hline Cyber-victim perspective & constrained equal & .226 & $<.001$ & .183 & .27 \\
\hline Participants' gender ${ }^{a}$ & constrained equal & .164 & $<.001$ & .113 & .214 \\
\hline Cyber-bystander perspective & constrained equal & .149 & $<.001$ & .116 & .182 \\
\hline Habits of smartphone/internet use during the day & constrained equal & .076 & $<.001$ & .044 & .108 \\
\hline Habits of smartphone/internet use during the week & constrained equal & .038 & .015 & .007 & .069 \\
\hline Participants'age & constrained equal & .014 & .078 & -.002 & .031 \\
\hline Parents' education & constrained equal & -.011 & .573 & -.047 & .026 \\
\hline Internet regulations & constrained equal & -.070 & $<.001$ & -.097 & -.043 \\
\hline
\end{tabular}

Note: a $0=$ Female, $1=$ Male. 
Table 5

Standardized solution for the multiple group model combining (H1) informational social in uence and (H2) referential informative social in uence path, with cyberbullying perpetration as the outcome variable.

\begin{tabular}{|c|c|c|c|c|c|}
\hline Path terms & Ingroup Prototipicality & Estimate & Signi cance & CI.lower & CI.upper \\
\hline Perceived peer-norm & constrained equal & .269 & $<.001$ & .226 & .313 \\
\hline Cyberspace regulations & constrained equal & -.092 & $<.001$ & -.125 & -.060 \\
\hline (H 1) Perceived peer-norm X Cyberspace regulations & constrained equal & -.062 & $<.001$ & -.099 & -.026 \\
\hline Ingroup identi cation & constrained equal & .048 & $<.001$ & .019 & .078 \\
\hline \multirow[t]{3}{*}{ (H2) Perceived peer-norm X Ingroup identi cation } & High & .190 & $<.001$ & .082 & .297 \\
\hline & Med & .040 & .167 & -.017 & .096 \\
\hline & Low & .086 & $<.001$ & .034 & .138 \\
\hline Cyber-victim perspective & constrained equal & .221 & $<.001$ & .177 & .265 \\
\hline Participants' gender ${ }^{a}$ & constrained equal & .176 & $<.001$ & .120 & .233 \\
\hline Cyber-bystander perspective & constrained equal & .167 & $<.001$ & .131 & .202 \\
\hline Habits of smartphone/internet use during the day & constrained equal & .084 & $<.001$ & .050 & .118 \\
\hline Habits of smartphone/internet use during the week & constrained equal & .036 & .031 & .003 & .069 \\
\hline Participants' age & constrained equal & .016 & .054 & .000 & .033 \\
\hline Parents' education & constrained equal & -.029 & .143 & -.068 & .010 \\
\hline Internet regulations & constrained equal & -.079 & $<.001$ & -.108 & -.050 \\
\hline
\end{tabular}

Note: a $0=$ Female, $1=$ Male.

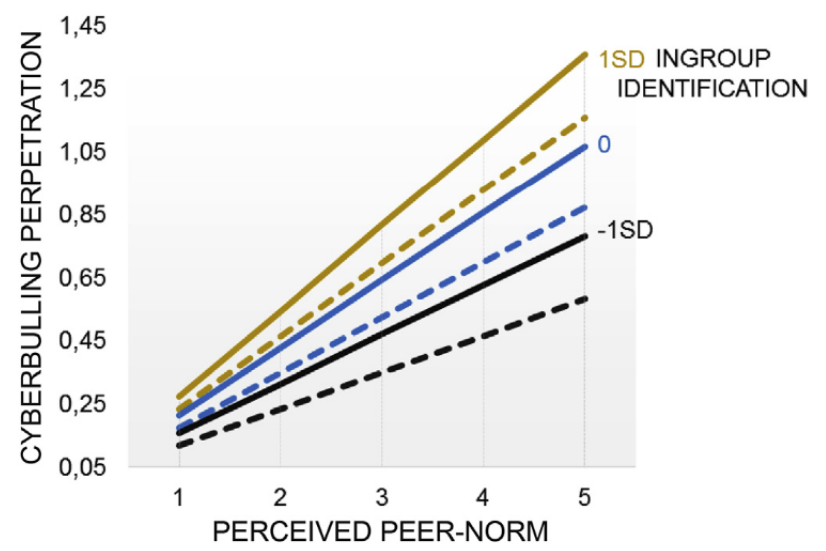

Fig. 2. Cyberbullying perpetration as a function of perceived peer-norm, ingroup identi cation $(-1,0,+1 \mathrm{SD})$, at $-1 \mathrm{SD}$ (dotted line) and at $+1 \mathrm{SD}$ (solid line) of ingroup prototypicality.

cyberbullying perpetration,

, $p<.001$. The cyber-bystander perspective was also a signi cant predictor of cyberbullying perpetration, $\quad, p<.001$. Internet regulations signi cantly reduced cyberbullying perpetration, $\quad, p<.001$. Finally, the amount of usage of Smartphone/Internet during the day was positively associated with the criterion, $\quad, p<.001$.

\subsection{Ancillary analyses}

As for the informational social in uence ndings (i.e., perceived peer-norm and cyberspace regulation interaction), two subgroups can be identi ed as a function of the strength of association ( user-dened within lavaan) between the perceived peer-norm and cyberbullying perpetration. Speci cally, participants with higher vs. lower levels of cyberspace regulations, the former being less sensitive to the perceived peer-norm in uence (i.e., positive scenario subgroup, ,$p<.001$ ) than the latter (i.e., negative scenario subgroup, $, p<.001)$. A similar procedure was applied to the results pertaining to the referential informative social in uence ndings (i.e., perceived peer-norm, ingroup identi cation, and ingroup prototypicality interaction). Speci cally, participants with lower vs. higher levels of ingroup identi cation and ingroup prototypicality, the former being less sensitive to the perceived peer-norm (i.e., positive scenario subgroup, $\quad, p<.001$ ) than the latter (i.e., negative scenario subgroup, $\quad, p<.001$ ). The comparison between the negative scenario subgroup in the referential informative social in uence to the negative scenario subgroup in the informational social in uence indicated an increased amount of predicted cyberbullying perpetration equal to $14 \%$ ( ratio $=1.140, S E=0.153, p<.001$; see Fig. 3 ). The comparison between the positive scenario subgroup in the referential informative social in uence to the positive scenario subgroup in the informational social in uence indicated a decreased amount of predicted cyberbullying perpetration equal to $22 \%$ ( ratio $=0.777$, $S E=0.227, p<.001)$.

\section{Discussion}

Driven by previous evidence showing that peer group expectations regarding cyberbullying behaviors in uence individual cyberbullying perpetration, the current study aims to deepen the understanding of such a relationship. Speci cally, we recast the association between the perceived peer group norms concerning cyberbullying behaviors and adolescents tendency to engage in cyberbullying behaviors within the broader theoretical frame of social in uence. Taking advantage of two distinct, albeit not mutually exclusive social in uence mechanisms, namely the informational social in uence and the referential informative

\section{Negative Scenario Subgroup}

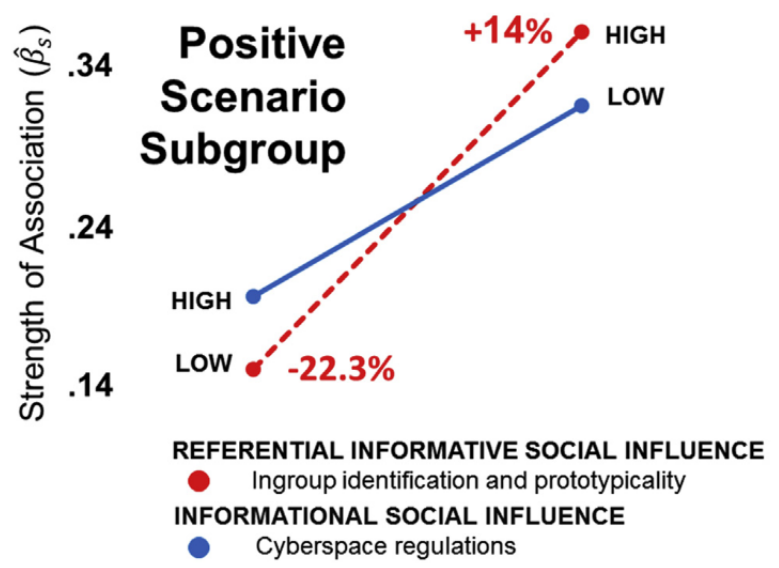

Fig. 3. Beta e ects of perceived peer-norm on cyberbullying perpetration in di erent sub-groups characterized according to speci c social in uence mechanisms. 
social in uence, we tested two di erent predictions.

First, in line with the informational social in uence mechanism (Hypothesis 1), we found that the higher the levels of perceived peernorm, the higher the level of cyberbullying perpetration at decreasing levels of cyberspace regulations. In other words, results indicated that the higher the levels of peer group norms supporting cyberbullying behaviors, the higher the levels of cyberbullying perpetration and that such a relationship is enhanced at decreasing levels of knowledge regarding the laws governing the use of cyberspace. In line with the informational social in uence mechanism, adolescents likely rely on the perceived group norms to guide their cyberbullying behaviors, especially when they lack knowledge regarding appropriate behavior in cyberspace. It is worth noting that even at high levels of cyberspace regulations, the association between the perceived peer-norm and cyberbullying perpetration was positive and statistically signi cant. This pattern of results indicates that higher levels of cyberspace regulations weaken but do not eliminate the association between perceived peernorm and cyberbullying perpetration.

Second, and according to the prediction derived from the referential informative social in uence mechanism (Hypothesis 2), the higher the levels of perceived peer-norm, the higher the levels of cyberbullying perpetration at increased levels of ingroup identi cation and ingroup prototypicality. Said otherwise, the results showed that the higher the support of group peer norms to cyberbullying behaviors, the stronger the likelihood that participants would engage in cyberbullying perpetration, and this association was moderated by participants' level of ingroup identi cation and ingroup prototypicality. Speci cally, we showed that the higher the level of ingroup identi cation and the higher the support of the group peer norms to cyberbullying behaviors, the higher the levels of adolescents tendency to engage in cyberbullying behaviors; this relation was even enhanced at increasing levels of ingroup prototypicality. This pattern of ndings provides evidence in favor of framing cyberbullying as a byproduct of a social identity-related process. Indeed, the relation between the perceived peer-norm and cyberbullying perpetration is rooted in the importance that adolescents attributed to the ingroup as an identity-de ning device as well as to the roles endorsed by the adolescents within the ingroup dynamics, these being either central or peripheral members. This pattern of ndings is coherent with predictions derived from the referential informative social in uence mechanism.

Together these ndings attest to the two types of social in uence mechanisms, informational and referential informative social in uence at work independently in shaping adolescents' cyberbullying behaviors. Given the co-occurrence of these two types of social in uence mechanisms, the ancillary analyses provide signi cant information for practical intervention. Indeed, at least in our sample, subgroups characterized as positive and negative based on the two models of social in uence showed that the referential informative social in uence is stronger than the informational social in uence in both positive and negative e ects. Said otherwise, successful interventions aimed at contrasting the referential informative social in uence would weaken the association between perceived peer-norm and participants' cyberbullying perpetration to a greater extent than successful interventions aimed at contrasting the informational social in uence. In addition, failing to address the referential informative social in uence would boost the association between perceived peer-norm and participants cyberbullying perpetration to a greater extent than failing to counteract informational social in uence.

Furthermore, the current study replicates previous ndings stemming from research addressing cyberbullying. First, being the victim of cyberbullying is associated with a high probability of engaging in cyberbullying perpetration. This result has been found in research on cyberbullying (Walrave \& Heirman, 2011; Ybarra \& Mitchell, 2004) as well as bullying in general (Olweus, 1997). Second, the cyber-bystander perspective was signi cantly and positively associated with cyber bullying perpetration. Speci cally, witnessing cyberbullying episodes enhanced the likelihood of engaging in cyberbullying behaviors, thus con rming the signi cant role played by the bystander perspective in shaping cyberbullying behaviors (Barlińska, Szuster, \& Winiewski, 2013; Bastiaensens et al., 2016; Kowalski, 2008).

Moreover, habits regarding Smartphone and Internet use per day was positively and signi cantly associated with cyberbullying perpetration. Indeed, more frequent daily on-line activity, as testi ed to by Smartphone and Internet usage, increased the likelihood of performing cyberbullying acts (for similar results, see Mishna et al., 2012; Rice et al., 2015).

As for the demographic variables, the current research contributed to understanding the associations between participants' gender, participants' age, parents' education, the frequency of Internet/Smartphone daily and weekly usage with cyberbullying perpetration. First, compared to male adolescents, female adolescents were less likely to be involved in cyberbullying perpetration. This nding is consistent with research carried out in the Italian context (Palermiti et al., 2017), and also in the European and American context (Li, 2006; Popović-Ćitić, Djurić, \& Cvetković, 2011; Quintana-Orts \& Rey, 2018), but were at odds with research reporting no association between participant gender and cyberbullying perpetration (DeHue et al., 2008; Griezel et al., 2012; Hinduja \& Patchin, 2008; Menesini et al., 2013; https://www. sciencedirect.com/science/article/pii/S0190740911003343, Smith et al., 2008; Williams \& Guerra, 2007; Ybarra \& Mitchell, 2004). Second, no signi cant association was found between participants' age and cyberbullying perpetration, in line with previous research showing that participants age was not a signi cant predictor of cyberbullying perpetration (Ste gen, König, Pfetsch, \& Melzer, 2011), but contrary to evidence suggesting a signi cant link between the variables in question (DeHue et al., 2008; Hinduja \& Patchin, 2008; Kowalski \& Limber, 2007; Ševčíková \& Šmahel, 2009; Ybarra et al., 2006, 2007).

Third, and as for parents level of education, the current result did not nd that this variable was a signi cant predictor of cyberbullying perpetration, as already reported by Makri-Botsari and Karagianni (2014).

Some limitations of the current study should be acknowledged. First, despite the sample size of our research being relatively large and representative of the geographic area in which the research was carried out, generalization of the current results to other cultural and social contexts should be made with caution. For instance, generalization should take into account that di erent geographical areas might have di erent laws regulating web usage, which could be di erent from laws regarding the same issue in Italy. Future investigation should be carried out in other cultural and geographic contexts to enhance the external validity of our results. Second, although the self-reporting questionnaires were anonymous, adolescents' answers may be guided, at least in part, by social desirability and self-presentation concerns (Brewer \& Kerslake, 2015; Davis, Thake, \& Vilhena, 2010). For example, participants' engaging in cyberbullying behaviors may have been underreported as well as the perceived peer group's cyberbullying acts. Future studies might take into consideration additional reporters (e.g., parents' or teachers' perspectives on cyberbullying behaviors) who can provide further signi cant information on this phenomenon. Third, and although the social in uence mechanisms we investigated in the present research stemmed from consolidating theoretical and empirical e orts, the cross-sectional nature of our study fails to clearly identify the causal direction of the reported e ects. Future studies should rely on longitudinal research to corroborate the pattern of associations observed in the present study.

\section{Conclusion}

In line with our results, the di usion of the cyberbullying phenomenon in the context under investigation appears to be worrisome, as more than one-third of the participants reported that they bullied someone, and more than one-third of participants responded that they 
were bullied at least sometimes. Together, these ndings signal the need of interventions aimed at counter-acting and preventing cyberbullying behaviors. First, and in line with our ndings, schools and educational services should work together to strengthen knowledge regarding online security and the responsible use of new technologies. Informative training could be scheduled in schools involving web security experts. However, our study also demonstrates that the knowledge about the appropriate behaviors in cyberspace is not e ective enough to prevent/reduce cyberbullying behaviors. Hence, parallel to interventions aimed at enhancing knowledge on the appropriate use of cyberspace, interventions based on peer education would be highly relevant. Indeed, as cyberbullying can be framed as a product of intragroup dynamics, interventions that take advantage of central members to promote anti-cyberbullying behaviors (i.e., peer education) could be successful in revising the peer norms regarding cyberbullying, and ultimately de ect the likelihood of engaging in such behaviors. Finally, given the higher gains of the latter over the former intervention, and the larger loss of not taking the latter over the former intervention, preventive strategies aimed at intervening in cyberbullying by targeting social identity dynamics are highly recommended, at least, by the current results.

\section{Acknowledgment}

We would like to thank Loredana Panariti, Ketty Segatti, Maria Graziella Pellegrini, Elisa Marzinotto- Regione Autonoma Friuli Venezia Giulia, Direzione centrale lavoro, formazione, istruzione e famiglia- for the support to this research. We would like also to thank Karoline Close for her careful review of our work.

\section{Appendix A. Supplementary data}

Supplementary data to this article can be found online at https://doi.org/10.1016/j.chb.2019.09.001.

\section{Appendix}

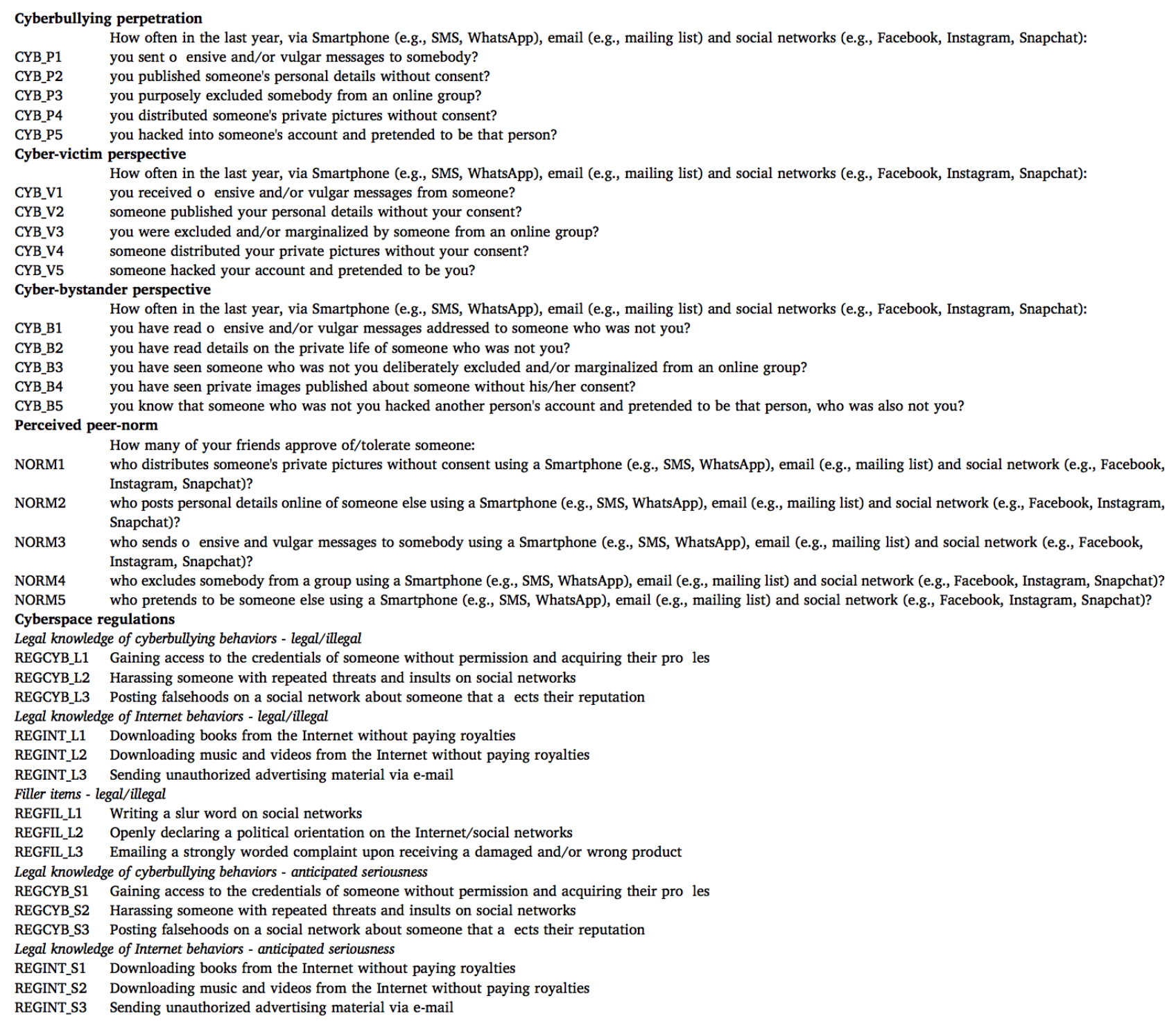


Filler items - anticipated seriousness

REGFIL_S1 Writing a slur word on social networks

REGFIL_S2 Openly declaring a political orientation on the Internet/social networks

REGFIL_S3 Emailing a strongly worded complaint upon receiving a damaged and/or wrong product

Ingroup prototypicality

PROT1 Think of your group of friends with whom you are in contact through Smartphone (e.g., SMS, WhatsApp), email (e.g., mailing list) and social networks (e.g., Facebook,

Instagram, Snapchat). How much do you feel typical (i.e., characteristic) of this group of friends with whom you are in contact through Smartphone (e.g., SMS,

Ingroup identification

WhatsApp), email (e.g., mailing list) and social networks (e.g., Facebook, Instagram, Snapchat)?

Cognitive identi cation

IDENT_IIS

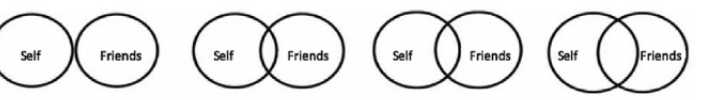

Inclusion of the Ingroup in the Self ( self and friends )

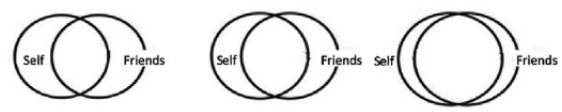

A ective identi cation (Kiesner et al., 2002)

IDENT_A1 Is it important for you to be a part of this group of friends?

IDENT_A2 If you are not a part of this group of friends, would you feel lonely?

IDENT_A3 Are you happy to be a part of this group of friends?

IDENT_A4 Are you proud to be a part of this group of friends?

IDENT_A5 If you weren't a part of this group of friends, would you be unhappy?

IDENT_A6 Are you happy to be described as a member of this group of friends?

IDENT_A7 Would you feel insecure if you were not a part of this group of friends?

IDENT_A8 Do you feel connected to the other members of this group of friends?

Habits regarding Smartphone/Internet use.

HAB1 Do you have a smartphone?

HAB2 Do you send or receive messages using a Smartphone?

HAB3 Do you send or receive messages using Internet?

HAB4 Are you part of a group via Smartphone?

HAB5 Are you part of a group via Internet?

HAB_SW During the week, how often do you use a Smartphone to send or receive messages?

HAB_IW During the week, how often do you use Internet to send or receive messages?

HAB_SD During the day, how often do you use a Smartphone to send or receive messages?

HAB_ID During the day, how often do you use Internet to send or receive messages?

\section{References}

Abrams, D., \& Hogg, M. (1990). Social identity theory: Constructive and critical advances. New York, NY: Springer-Verlag.

Aricak, T., Siyahhan, S., Uzunhasanoglu, A., Saribeyoglu, S., Ciplak, S., Yilmaz, N., et al. (2008). Cyberbullying among Turkish adolescents. CyberPsychology and Behavior, 11(3), 253 261. https://doi.org/10.1089/cpb.2007.0016.

Arnarsson, A., Nygren, J., Nyholm, M., Torsheim, T., Augustine, L., Bjereld, Y., Bendtsen, P. (2019). Cyberbullying and traditional bullying among Nordic adolescents and their impact on life satisfaction. Scandinavian Journal of Public Health. https://doi.org/10.1177/1403494818817411.

Aron, A., Aron, E. N., \& Smollan, D. (1992). Inclusion of other in the self scale and the structure of interpersonal closeness. Journal of Personality and Social Psychology, 63(4), 596 612. https://doi.org/10.1037/0022-3514.63.4.596.

Aron, A., Aron, E. N., Tudor, M., \& Nelson, G. (1991). Close relationships as including other in the self. Journal of Personality and Social Psychology, 60, 241 253. https:// doi.org/10.1037/0022-3514.60.2.241.

Baker, R. K., \& White, K. M. (2010). Predicting adolescents' use of social networking sites from an extended theory of planned behaviour perspective. Computers in Human Behavior, 26(6), 1591 1597. https://doi.org/10.1016/j.chb.2010.06.006.

Baldry, A. C., Farrington, D. P., \& Sorrentino, A. (2015). Am I at risk of cyberbullying ? A narrative review and conceptual framework for research on risk of cyberbullying and cybervictimization: The risk and needs assessment approach. Aggression and Violent cybervictimization: The risk and needs assessment approach. Agg
Behavior, 23, 36 51. https://doi.org/10.1016/j.avb.2015.05.014.

Barlińska, J., Szuster, A., \& Winiewski, M. (2013). Cyberbullying among adolescent bystanders: Role of the communication medium, form of violence, and empathy. Journal of Community \& Applied Social Psychology, 23(1), 37 51. https://doi.org/10.1002/ casp. 2137.

Baroncelli, A., \& Ciucci, E. (2014). Unique e ects of di erent components of trait emotional intelligence in traditional bullying and cyberbullying. Journal of Adolescence, 37(6), 807 815. https://doi.org/10.1016/j.adolescence.2014.05.009.

Bastiaensens, S., Pabian, S., Vandebosch, H., Poels, K., Van Cleemput, K., DeSmet, A., et al. (2016). From normative in uence to social pressure: How relevant others a ect whether bystanders join in cyberbullying. Social Development, 25(1), 193211. https://doi.org/10.1111/sode.12134.

Bentler, P. M. (1990). Comparative $\mathrm{t}$ indexes in structural models. Psychological Bulletin, 107, 238246.

Beran, T., \& Li, Q. (2008). The relationship between cyberbullying and school bullying. The Journal of Student Wellbeing, 1(2), 16 33. https://doi.org/10.21913/JSW.v1i2. 172.

Bhat, C. S. (2008). Cyber bullying: Overview and strategies for school counsellors, guidance o cers, and all school personnel. Journal of Psychologists and Counsellors in
Schools, 18(1), 53 66. https://doi.org/10.1375/ajgc.18.1.53.

Brewer, G., \& Kerslake, J. (2015). Cyberbullying, self-esteem, empathy and loneliness. Computers in Human Behavior, 48, 255 260. https://doi.org/10.1016/j.chb.2015.01. 073.

Brighi, A., Guarini, A., Melotti, G., Galli, S., \& Genta, M. L. (2012). Predictors of victimisation across direct bullying, indirect bullying and cyberbullying. Emotional \& Behavioural Di culties, 17, 375 388. https://doi.org/10.1080/13632752.2012. 704684.

Brighi, A., Menin, D., Skrzypiec, G., \& Guarini, A. (2019). Young, bullying, and connected. Common pathways to cyberbullying and problematic internet use in adolescence. Frontiers in Psychology, 10. https://doi.org/10.3389/fpsyg.2019.01467.

Brochado, S., Soares, S., \& Fraga, S. (2017). A scoping review on studies of cyberbullying prevalence among adolescents. Trauma, Violence, \& Abuse, 18(5), 523 531. https:// doi.org/10.1177/1524838016641668.

Calvete, E., Orue, I., Estévez, A., Villardón, L., \& Padilla, P. (2010). Cyberbullying in adolescents: Modalities and aggressors' pro le. Computers in Human Behavior, 26 1128 1135. https://doi.org/10.1016/j.chb.2010.03 .017.

Camp eld, D. C. (2008). Cyber bullying and victimization: Psychosocial characteristics of bullies, victims, and bully/victims(Unpublished doctoral dissertation). USA: University of Montana Missoula, MT.

Carnaghi, A., \& Yzerbyt, V. Y. (2006). Social consensus and the encoding of consistent and inconsistent information: When one's future audience orients information processing. European Journal of Social Psychology, 36(2), 199 210. https://doi.org/10.1002/ejsp. 265.

Carnaghi, A., \& Yzerbyt, V. Y. (2007). Subtyping and social consensus: The role of the audience in the maintenance of stereotypic beliefs. European Journal of Social Psychology, 37(5), 902 922. https://doi.org/10.1002/ejsp.402.

Cialdini, R. B. (1993). In uence: The psychology of persuasion. New York: Quill.

Craig, W. M., Pepler, D., \& Atlas, R. (2000). Observations of bullying in the playground and in the classroom. School Psychology International, 21(1), 22 36. https://doi.org/ $10.1177 / 0143034300211002$.

Davis, C. G., Thake, J., \& Vilhena, N. (2010). Social desirability biases in self-reported alcohol consumption and harms. Addictive Behaviors, 35, 302 311. https://doi.org/ 10.1016/j.addbeh.2009.11.001.

DeHue, F., Bolman, C., \& Völlink, T. (2008). Cyberbullying: Youngsters' experiences and parental perception. CyberPsychology and Behavior, 11(2), 217 223. https://doi.org/ $10.1089 / \mathrm{cpb} .2007 .0008$.

Del Rey, R., Casas, J. A., Ortega-Ruiz, R., Schultze-Krumbholz, A., Scheithauer, H., Smith, P., ... Guarini, A. (2015). Structural validation and cross-cultural robustness of the european cyberbullying intervention project questionnaire. Computers in Human Behavior, 50, 141 147. https://doi.org/10.1016/j.chb.2015.03.065.

DeSmet, A., Veldeman, C., Poels, K., Bastiaensens, S., Van Cleemput, K., Vandebosch, H., et al. (2014). Determinants of self-reported bystander behavior in cyberbullying 
incidents amongst adolescents. Cyberpsychology, Behavior, and Social Networking, 17, 207 215. https://doi.org/10.1089/cyber.2013.0027.

Deutsch, M., \& Gerard, H. B. (1955). A study of normative and informational social inuences upon individual judgement. Journal of Abnormal and Social Psychology, 51, 629 636. https://doi.org/10.1037/h0046408.

Dovidio, J. F., Evans, N., \& Tyler, R. B. (1986). Racial stereotypes: The contents of their cognitive representations. Journal of Experimental Social Psychology, 22(1), 2237. https://doi.org/10.1016/0022-1031(86)90039-9.

Du y, A. L., \& Nesdale, D. (2009). Peer groups, social identity, and children's bullying behavior. Social Development, 18(1), 121 139. https://doi.org/10.1111/j.1467-9507. 2008.00484.x.

Du y, A. L., \& Nesdale, D. (2010). Group norms, intra-group position and children's aggressive intentions. European Journal of Developmental Psychology, 7(6), 696716. https://doi.org/10.1080/17405620903132504.

Easterbrook, M., \& Vignoles, V. L. (2013). What does it mean to belong? Interpersonal bonds and intragroup similarities as predictors of felt belonging in di erent types of groups. European Journal of Social Psychology, 43(6), 455 462. https://doi.org/10. 1002/ejsp.1972.

Espelage, D. L., \& Swearer, S. M. (2003). Research on school bullying and victimization: What have we learned and where do we go from here? [Mini-series]. School Psychology Review, 12(3), 365383.

Fanti, K. A., Demetriou, A. G., \& Hawa, V. V. (2012). A longitudinal study of cyberbullying: Examining risk and protective factors. European Journal of Developmental Psychology, 9, 168 181. https://doi.org/10.1080/17405629.2011.643169.

Festinger, L., Schacter, S., \& Back, K. (1950). Social pressures, informal groups. New York, NY: Holt Rinehart \& Winston.

Festl, R., Scharkow, M., \& Quandt, T. (2013). Problematic computer game use among adolescents, younger and older adults. Addiction, 108(3), 592 599. https://doi.org/ 10.1111/add.12016.

Festl, R., Vogelgesang, J., Scharkow, M., \& Quandt, T. (2017). Longitudinal patterns of involvement in cyberbullying: Results from a latent transition analysis. Computers in Human Behavior, 66, 7 15. https://doi.org/10.1016/j.chb.2016.09.027.

Fiske, S. T. (1982). Schema-triggered a ect: Applications to social perception. In M. S. Clark, \& S. T. Fiske (Eds.). A ect and cognition: The 17th annual carnegie symposium on cognition (pp. 55 78). Hillsdale, NJ: Erlbaum.

French, J., \& Raven, B. (1959). The bases of social power. In D. Cartwright (Ed.). Studies in social power (pp. 150 167). Oxford, England: Univer. Michigan.

Ga ney, H., Farrington, D. P., Espelage, D. L., \& Tto , M. M. (2018). Are cyberbullying intervention and prevention programs e ective? A systematic and meta-analytical review. Aggression and Violent Behavior, 45, 134 153. https://doi.org/10.1016/j.avb. 2018.07.002.

Genta, M., Brighi, A., \& Guarini, A. (2009). European project on bullying and cyberbullying granted by Daphne II programme. Zeitschrift für Psychologie Journal of Psychology, 217(4), 233. https://doi.org/10.1027/0044-3409.217.4.233.

Goode, C., Balzarini, R. H., \& Smith, H. J. (2014). Positive peer pressure: Priming member prototypicality can decrease undergraduate drinking. Journal of Applied Social Psychology, 44(8), 567 578. https://doi.org/10.1111/jasp.12248.

Görzig, A., \& Frumkin, L. (2013). Cyberbullying experiences on-the-go: When socia media can become distressing. Cyberpsychology: Journal of Psychosocial Research on Cyberspace, 18(8), 1194 1213. https://doi.org/10.5817/CP2013-1-4.

Gradinger, P., Strohmeier, D., \& Spiel, C. (2009). Traditional bullying and cyberbullying: Identi cation of risk groups for adjustment problems. Zeitschrift für Psychologie Journal of Psychology, 217(4), 205 213. https://doi.org/10.1027/0044-3409.217.4. 205.

Griezel, L., Finger, L. R., Bodkin-Andrews, G. H., Craven, R. G., \& Yeung, A. S. (2012). Uncovering the structure of and gender and developmental di erences in cyber bullying. The Journal of Educational Research, 105(6), 442 455. https://doi.org/10. $1080 / 00220671.2011 .629692$.

Guarini, A., Passini, S., Melotti, G., \& Brighi, A. (2012). Protective factors on perpetration of bullying and cyberbullying. Studia Edukacyjne, 23, 3355.

Hamilton, K., \& White, K. M. (2008). Extending the theory of planned behavior: The role of self and social in uences in predicting adolescent regular moderate-to-vigorous physical activity. Journal of Sport \& Exercise Psychology, 30(1), 56 74. https://doi. org/10.1123/jsep.30.1.56.

Hasebrink, U., Livingstone, S., Haddon, L., \& Ólafsson, K. (2009). Comparing children's online opportunities and risks across Europe: Cross-national comparisons for EU Kids Online (2nd ed.). LSE, London: EU Kids Online.

Heirman, W., \& Walrave, M. (2012). Predicting adolescent perpetration in cyberbullying: An application of the theory of planned behavior. Psicothema, 24, 614620.

Hinduja, S., \& Patchin, J. W. (2008). Cyberbullying: An exploratory analysis of factors related to o ending and victimization. Deviant Behavior, 29(2), 129 156. https://doi. org/10.1080/01639620701457816.

Hinduja, S., \& Patchin, J. (2013). Social in uences on cyberbullying behaviors amon middle and high school students. Journal of Youth and Adolescence, 42, 711722. https://doi.org/10.1007/s10964-012-9902-4.

Hogg, M. A. (2007). Uncertainty identity theory. Advances in Experimental Social Psychology, 39, 69 126. https://doi.org/10.1016/S0065-2601(06)39002-8.

Hogg, M. A., Abrams, D., Otten, S., \& Hinkle, S. (2004). The social identity perspective: Intergroup relations, self-conception, and small groups. Small Group Research, 35(3), 246 276. https://doi.org/10.1177/1046496404263424.

Hu, L., \& Bentler, P. M. (1998). Fit indices in covariance structure modeling: Sensitivity to underparameterized model misspeci cation. Psychological Methods, 3(4), 424453.

Hu, L. T., \& Bentler, P. M. (1999). Cuto criteria for $t$ indexes in covariance structure analysis: Conventional criteria versus new alternatives. Structural Equation Modeling: A Multidisciplinary Journal, 6(1), 1 55. https://doi.org/10.1080/ 107055199909540118https://doi.org/10.1080/10705519909540118.
Huber, P. J. (1967). The behaviour of Maximum likelihood estimates under nonstandard conditions. Proceedings of the Fifth Berkeley Symposium: 4, (pp. 221 233),

Istituto Nazionale di Statistica (2014). Il bullismo in italia: Comportamenti o ensivi e violenti tra i giovanissimi. Retrieved from https://www.istat.it/it/ les/2015/12/ Bullismo.pdf.

Jadambaa, A., Thomas, H. J., Scott, J. G., Graves, N., Brain, D., \& Pacella, R. (2019). Prevalence of traditional bullying and cyberbullying among children and adolescents in Australia: A systematic review and meta-analysis. Australian and New Zealand Journal of Psychiatry. https://doi.org/10.1177/0004867419846393.

Jetten, J., \& Spears, R. (2003). The divisive potential of di erences and similarities: The role of intergroup distinctiveness in intergroup di erentiation. European Review of Social Psychology, 14(1), 203 241. https://doi.org/10.1080/10463280340000063.

Jetten, J., Spears, R., \& Manstead, A. S. (1997). Strength of identi cation and intergroup di erentiation: The in uence of group norms. European Journal of Social Psychology, 27(5), 603 609. https://doi.org/10.1002/(SICI)1099-0992(199709/10) 27:5<603:AID-EJSP816>3.0.CO;2-B.

Kashima, E. S., Kashima, Y., \& Hardie, E. A. (2000). Self-typicality and group identi cation: Evidence for their separateness. Group Processes \& Intergroup Relations, 3(1), 97 110. https://doi.org/10.1177/1368430200031006.

Kiesner, J., Cadinu, M., Poulin, F., \& Bucci, M. (2002). Group identi cation in early adolescence: Its relation with peer adjustment and its moderator e ect on peer inuence. Child Development, 73(1), 196 208. https://doi.org/10.1111/1467-8624. 00400.

Kiriakidis, S. P., \& Kavoura, A. (2010). Cyberbullying: A review of the literature on harassment through the internet and other electronic means. Family \& Community Health, 33(2), 82 93. https://doi.org/10.1097/FCH.0b013e3181d593e4.

Klink, A., Mummendey, A., Mielke, R., \& Blanz, M. (1998). A multicomponent approach to group identi cation: Di erential prediction of intergroup behavior by cognitive and a ective components of identi cation. (Unpublished Manuscript).

Kowalski, R. M. (2008). Cyber bullying: Recognizing and treating victim and aggressor. Psychiatric Times, 25(11), 4547.

Kowalski, R. M., Giumetti, G. W., Schroeder, A. N., \& Lattanner, M. R. (2014). Bullying in the digital age: A critical review and meta-analysis of cyberbullying research among youth. Psychological Bulletin, 140(4), 1073 1137. https://doi.org/10.1037/ a0035618.

Kowalski, R. M., \& Limber, S. P. (2007). Electronic bullying among middle school students. Journal of Adolescent Health, 41(6), S22 S30. https://doi.org/10.1016/j. jadohealth.2007.08.017.

Kowalski, R. M., Limber, S. P., \& Agatston, P. W. (2008). Cyberbullying. Malden, MA: Blackwell.

Kowalski, R. M., Limber, S. P., \& McCord, A. (2019). A developmental approach to cyberbullying: Prevalence and protective factors. Aggression and Violent Behavior, 45, 20 32. https://doi.org/10.1016/j.avb.2018.02.009.

Låftman, S. B., Modin, B., \& Östberg, V. (2013). Cyberbullying and subjective health: A large-scale study of students in stockholm, Sweden. Children and Youth Services Review, 35(1), 112 119. https://doi.org/10.1016/j.childyouth.2012.10.020.

Langos, C. (2012). Cyberbullying: The challenge to de ne. Cyberpsychology, Behavior, and Social Networking, 15(6), 285 289. https://doi.org/10.1089/cyber.2011.0588.

Li, Q. (2006). Cyberbullying in schools: A research of gender di erences. School Psychology International, 27, 157 170. https://doi.org/10.1177/0143034306064547.

Li, Q. (2007). New bottle but old wine: A research of cyberbullying in schools. Computers in Human Behavior, 23, 1777 1791. https://doi.org/10.1016/j.chb.2005.10.005.

Li, Q., Smith, P., \& Cross, D. (2012). Research into cyberbullying: Context. In Q. Li, D. Cross, \& P. Smith (Eds.). Cyberbullying in the global playground: Research from international perspectives (pp. 3 12). Malden, MA: Blackwell.

Liu, Q. X., Fang, X. Y., Deng, L. Y., \& Zhang, J. T. (2012). Parent adolescent communication, parental Internet use and Internet-speci $\mathrm{c}$ norms and pathological Internet use among Chinese adolescents. Computers in Human Behavior, 28(4), 12691275. https://doi.org/10.1016/j.chb.2012.02.010.

Lobe, B., Livingstone, S., Ólafsson, K., \& Vodeb, H. (2011). Cross-national comparison of risks and safety on the Internet: Initial analysis from the EU Kids online survey of european children. London: EU Kids Online, LSE.

Louis, W. R., Taylor, D. M., \& Douglas, R. L. (2005). Normative in uence and rational con ict decisions: Group norms and cost-bene $t$ analyses for intergroup behavior. Group Processes \& Intergroup Relations, 8(4), 355 374. https://doi.org/10.1177/ 1368430205056465.

Makri-Botsari, E., \& Karagianni, G. (2014). Cyberbullying in Greek adolescents: The role of parents. Procedia-Social and Behavioral Sciences, 116, 3241 3253. https://doi.org/ 10.1016/j.sbspro.2014.01.742.

Malcolm, S., Huang, S., Cordova, D., Freitas, D., Arzon, M., Jimenez, G. L., \& Prado, G. (2013). Predicting condom use attitudes, norms, and control beliefs in Hispanic problem behavior youth: The e ects of family functioning and parent adolescent communication about sex on condom use. Health Education \& Behavior, 40(4), 384 391. https://doi.org/10.1177/1090198112440010.

Méndez, E., Gómez, Á., \& Tropp, L. R. (2007). When metaperceptions are a ected by intergroup processes. International Journal of Psychology and Psychological Therapy, $7(2), 237250$.

Menesini, E., \& Nocentini, A. (2009). Cyberbullying de nition and measurement: Some critical considerations. Zeitschrift für Psychologie Journal of Psychology, 217(4), 230 232. https://doi.org/10.1027/0044-3409.217.4.230.

Menesini, E., Nocentini, A., \& Camodeca, M. (2013). Morality, values, traditional bullying, and cyberbullying in adolescence. British Journal of Developmental Psychology, 31(1), 1 14. https://doi.org/10.1111/j.2044-835X.2011.02066.x.

Mishna, F., Khoury-Kassabri, M., Gadalla, T., \& Daciuk, J. (2012). Risk factors for involvement in cyber bullying: Victims, bullies and bully victims. Children and Youth Services Review, 34(1), 63 70. https://doi.org/10.1016/j.childyouth.2011.08.032. 
Modecki, K. L., Minchin, J., Harbaugh, A. G., Guerra, N. G., \& Runions, K. C. (2014). Bullying prevalence across contexts: A meta-analysis measuring cyber and traditional bullying. Journal of Adolescent Health, 55, 602 611. https://doi.org/10.1016/j. jadohealth.2014.06.007.

Nocentini, A., Calmaestra, J., Schultze-Krumbholz, A., Scheithauer, H., Ortega, R., \& Menesini, E. (2010). Cyberbullying: Labels, behaviours and de nition in three European countries. Journal of Psychologists and Counsellors in Schools, 20(2), 129 142. https://doi.org/10.1375/ajgc.20.2.129.

O'Connell, P., Pepler, D., \& Craig, W. (1999). Peer involvement in bullying: Insights and challenges for intervention. Journal of Adolescence, 22(4), 437 452. https://doi.org/ 10.1006/jado.1999.0238.

Obst, P., White, K., Mavor, K., \& Baker, R. (2011). Social identi cation dimensions as mediators of the e ect of prototypicality on intergroup behaviours. Psychology, 2(5), 426 432. https://doi.org/10.4236/psych.2011.25066.

Oh, I., \& Hazler, R. J. (2009). Contributions of personal and situational factors to bystanders' reactions to school bullying. School Psychology International, 30, 291310. https://doi.org/10.1177/0143034309106499.

Olweus, D. (1997). Bully/victim problems in school: Facts and intervention. European Journal of Psychology of Education, 12(4), 495 510. https://doi.org/10.1007/ BF03172807.

Pabian, S., \& Vandebosch, H. (2014). Using the theory of planned behaviour to understand cyberbullying: The importance of beliefs for developing interventions. European Journal of Developmental Psychology, 11(4), 463 477. https://doi.org/10.1080/ Journal of Developmental

Palermiti, A. L., Servidio, R., Bartolo, M. G., \& Costabile, A. (2017). Cyberbullying and self-esteem: An Italian study. Computers in Human Behavior, 69, 136 141. https://doi org/10.1016/j.chb.2016.12.026.

Popović-Ćitić, B., Djurić, S., \& Cvetković, V. (2011). The prevalence of cyberbullying among adolescents: A case study of middle schools in Serbia. School Psycholog/ International, 32(4), 412 424. https://doi.org/10.1177/0143034311401700.

Pozzoli, T., \& Gini, G. (2010). Active defending and passive bystanding behavior in bullying: The role of personal characteristics and perceived peer pressure. Journal of Abnormal Child Psychology, 38(6), 815 827. https://doi.org/10.1007/s10802-0109399-9.

Pozzoli, T., \& Gini, G. (2019). Behavior during cyberbullying episodes: Initial validation of a new self report scale. Scandinavian Journal of Psychology. https://doi.org/10. 1111 sjop.12517.

Pyżalski, J. (2012). From cyberbullying to electronic aggression: Typology of the phenomenon. Emotional \& Behavioural Di culties, 17(3 4), 305 317. https://doi.org/10. 1080/13632752.2012.704319.

Quintana-Orts, C., \& Rey, L. (2018). Forgiveness and cyberbullying in adolescence: Does willingness to forgive help minimize the risk of becoming a cyberbully? Computers in Human Behavior, 81, 209 214. https://doi.org/10.1016/j.chb.2017.12.021.

$\mathrm{R}$ Core Team (2018). R: A language and environment for statistical computing. Vienna, Austria: R Foundation for Statistical Computing. Retrieved from https://www.Rproject.org/.

Rice, E., Petering, R., Rhoades, H., Winetrobe, H., Goldbach, J., Plant, A.,., \& Kordic, T. (2015). Cyberbullying perpetration and victimization among middle-school students. American Journal of Public Health, 105(3), 66 72. https://doi.org/10.2105/AJPH. 2014.302393.

Rosseel, Y. (2012). Lavaan: An R package for structural equation modeling and more. Version 0.512 (BETA). Journal of Statistical Software, 48(2), 136.

Salmivalli, C. (1999). Participant role approach to school bullying: Implications for interventions. Journal of Adolescence, 22(4), 453 459. https://doi.org/10.1006/jado. 1999.0239.

Sasson, H., \& Mesch, G. (2014). Parental mediation, peer norms and risky online behavior among adolescents. Computers in Human Behavior, 33, 32 38. https://doi.org/10. 1016/j.chb.2013.12.025

Sasson, H., \& Mesch, G. (2017). The role of parental mediation and peer norms on the likelihood of cyberbullying. The Journal of Genetic Psychology, 178, 15 27. https:// doi.org/10.1080/00221325.2016.1195330.

Satorra, A., \& Bentler, P. M. (2001). A scaled di erence chi-square test statistic for moment structure analysis. Psychometrika, 66(4), 507 514. https://doi.org/10.1007/ BF02296192.

Satorra, A., \& Bentler, P. M. (2010). Ensuring positiveness of the scaled di erence chisquare test statistic. Psychometrika, 75(2), 243 248. https://doi.org/10.1007/ s11336-009-9135-y.

Schenk, A. M., \& Fremouw, W. J. (2012). Prevalence, psychological impact, and coping of cyberbully victims among college students. Journal of School Violence, 11(1), 2137. https://doi.org/10.1080/15388220.2011.630310.

Schermelleh-Engel, K., Moosbrugger, H., \& Müller, H. (2003). Evaluating the $t$ of structural equation models: Tests of signi cance and descriptive goodness-of- t measures. Methods of Psychological Research Online, 8(2), 2374.

Schmitt, M. T., \& Branscombe, N. R. (2001). The good, the bad, and the manly: Threats to one's prototypicality and evaluations of fellow in-group members. Journal of Experimental Social Psychology, 37(6), 510 517. https://doi.org/10.1006/jesp.2001. 1476 .

Schubert, T. W., \& Otten, S. (2002). Overlap of self, ingroup, and outgroup: Pictorial measures of self-categorization. Self and Identity, 1(4), 353 376. https://doi.org/10. 1080/152988602760328012.

Schultze-Krumbholz, A., Göbel, K., Scheithauer, H., Brighi, A., Guarini, A., Tsorbatzoudis, H.,., \& Casas, J. A. (2015). A comparison of classi cation approaches for cyberbullying and traditional bullying using data from six European countries. Journal of
School Violence, 14(1), 47 65. https://doi.org/10.1080/15388220.2014.961067.

Ševčíková, A., \& Šmahel, D. (2009). Online harassment and cyberbullying in the Czech Republic: Comparison across age groups. Zeitschrift für Psychologie Journal of Psychology, 217(4), 227 229. https://doi.org/10.1027/0044-3409.217.4.227.

Smith, P. K. (2012). Cyberbullying and cyber aggression. In R. S. Jimerson, B. A. Nickerson, J. M. Mayer, \& J. M. Furlong (Eds.). Handbook of school violence and school safety: International research and practice (pp. 93 103). New York, NY: Routledge.

Smith, P. K., Mahdavi, J., Carvalho, M., Fisher, S., Russell, S., \& Tippett, N. (2008). Cyberbullying: Its nature and impact in secondary school pupils. Journal of Child Psychology and Psychiatry, 49, 376 385. https://doi.org/10.1111/j.1469-7610.2007. 01846.x.

Ste gen, G., König, A., Pfetsch, J., \& Melzer, A. (2011). Are cyberbullies less empathic? Adolescents' cyberbullying behavior and empathic responsiveness. Cyberpsychology, Behavior, and Social Networking, 14, 643 648. https://doi.org/10.1089/cyber.2010. 0445.

Steiger, J. H., \& Lind, J. (1980). Statistically based tests for the number of common factors. Paper presented at the annual meeting of the psychometric society, Iowa city.

Tajfel, H., \& Turner, J. C. (1979). An integrative theory of intergroup con ict. In W. G. Austin, \& S. Worchel (Eds.). The social psychology of intergroup relations (pp. 33 47) Monterey, CA: Brooks/Cole.

Terry, D. J., \& Hogg, M. A. (1996). Group norms and the attitude-behavior relationship: A role for group identi cation. Personality and Social Psychology Bulletin, 22(8), 776 793. https://doi.org/10.1177/0146167296228002.

Tokunaga, R. S. (2010). Following you home from school: A critical review and synthesis of research on cyberbullying victimization. Computers in Human Behavior, 26(3), 277 287. https://doi.org/10.1016/j.chb.2009.11.014

Tropp, L. R., \& Wright, S. C. (2001). Ingroup identi cation as the inclusion of ingroup in the self. Personality and Social Psychology Bulletin, 27(5), 585 600. https://doi.org/10. $1177 / 0146167201275007$.

Turner, J. C. (1985). Social categorization and the self-concept: A social cognitive theory of group behavior. Advances in Group Processes, 2, 77122.

Turner, J. C. (1991). Social in uence. Buckingham, England: Open University Press.

Turner, J. C., Hogg, M. A., Oakes, P. J., Reicher, S. D., \& Wetherell, M. S. (1987), Rediscovering the social group: A self-categorization theory. Cambridge, MA: Basi Blackwell.

Tuscherer, T., \& Hugenberg, K. (2014). What's love got to do with it? Sexual prejudice predicts unitization of men in same-sex romantic relationships. Journal of Experimental Social Psychology, 52, 9 14. https://doi.org/10.1016/j.jesp.2013.12. 002.

Ubertini, M. (2011). Cyberbullying may reduce adolescent's well-being: Can life satisfaction and social support protect them?(Doctoral dissertation). Retrieved from Dissertation Abstracts International.

Vandebosch, H., \& Van Cleemput, K. (2008). De ning cyberbullying: A qualitative research into the perceptions of youngsters. CyberPsychology and Behavior, 11(4), 499 503. https://doi.org/10.1089/cpb.2007.0042.

Walrave, M., \& Heirman, W. (2011). Cyberbullying: Predicting victimisation and perpetration. Children \& Society, 25(1), 59 72. https://doi.org/10.1111/j.1099-0860.2009. 00260.x.

Wang, J., Iannotti, R. J., \& Nansel, T. R. (2009). School bullying among adolescents in the United States: Physical, verbal, relational, and cyber. Journal of Adolescent Health, 45, 368 375. https://doi.org/10.1016/j.jadohealth .2009.03.021.

White, H. (1980). A heteroskedasticity-consistent covariance matrix estimator and a direct test for heteroskedasticity. Econometrica, 48, 817838

White, K. M., Hogg, M. A., \& Terry, D. J. (2002). Improving attitude-behavior correspondence through exposure to normative support from a salient ingroup. Basic and Applied Social Psychology, 24(2), 91 103. https://doi.org/10.1207/ S1532383BASP2402_2.

White, K. M., Smith, J. R., Terry, D. J., Greenslade, J. H., \& McKimmie, B. M. (2009). Social in uence in the theory of planned behaviour: The role of descriptive, injunctive, and in group norms. British Journal of Social Psychology, 48(1), 135158. https://doi.org/10.1348/014466608X295207.

Willard, N. E. (2007). Cyberbullying and cyberthreats: Responding to the challenge of online social aggression, threats, and distress. Champaign, IL: Research Press.

Williams, K. R., \& Guerra, N. G. (2007). Prevalence and predictors of Internet bullying Journal of Adolescent Health, 41(6), 14 21. https://doi.org/10.1016/j.jadohealth. 2007.08.018.

Yang, A., \& Salmivalli, C. (2013). Di erent forms of bullying and victimization: Bullyvictims versus bullies and victims. European Journal of Developmental Psychology, 10(6), 723 738. https://doi.org/10.1080/17405629.2013.793596.

Ybarra, M. L., \& Mitchell, K. J. (2004). Youth engaging in online harassment: Associations with caregiver-child relationships, Internet use, and personal characteristics. Journal of Adolescence, 27, 319 336. https://doi.org/10.1016/j.adolescence.2004.03.007.

Ybarra, M. L., Mitchell, K. J., Finkelhor, D., \& Wolak, J. (2007). Internet prevention messages: Targeting the right online behaviors. Archives of Pediatrics and Adolescent Medicine, 161(2), 138 145. https://doi.org/10.1001/archpedi.161.2.138D.

Ybarra, M. L., Mitchell, K. J., Wolak, J., \& Finkelhor, D. (2006). Examining characteristics and associated distress related to internet harassment: Findings from the second youth internet safety survey. Pediatrics, 118(4), 11691177.

Yuan, K. H., \& Bentler, P. M. (1998). Structural equation modeling with robust covariances. Sociological Methodology, 28(1), 363 396. https://doi.org/10.1111/00811750.00052. 
